\title{
Interconnection-wide Hour-ahead Scheduling in the Presence of Intermittent Renewables and Demand Response: a Surplus Maximizing Approach
}

\author{
Sahand Behboodi ${ }^{\mathrm{a}, *}$, David P. Chassin ${ }^{\mathrm{a}, \mathrm{b}}$, Ned Djilali ${ }^{\mathrm{a}, \mathrm{c}}$, Curran Crawford $^{\mathrm{a}}$ \\ ${ }^{a}$ Institute for Integrated Energy Systems, and Department of Mechanical Engineering, \\ University of Victoria, Victoria, British Columbia, Canada \\ ${ }^{b}$ SLAC National Accelerator Laboratory, Menlo Park, California, USA \\ ${ }^{c}$ Renewable Energy Research Group, King Abdulaziz University, Jeddah, Saudi Arabia
}

\begin{abstract}
This paper describes a new approach for solving the multi-area electricity resource allocation problem when considering both intermittent renewables and demand response. The method determines the hourly inter-area export/import set that maximizes the interconnection (global) surplus satisfying transmission, generation and load constraints. The optimal inter-area transfer set effectively makes the electricity price uniform over the interconnection apart from constrained areas, which overall increases the consumer surplus more than it decreases the producer surplus. The method is computationally efficient and suitable for use in simulations that depend on optimal scheduling models. The method is demonstrated on a system that represents North America Western Interconnection for the planning year of 2024. Simulation results indicate that effective use of interties reduces the system operation cost substantially. Excluding demand response, both the unconstrained and the constrained scheduling solutions decrease the global production cost (and equivalently increase the global economic surplus) by $\$ 12.30 \mathrm{~B}$ and $\$ 10.67 \mathrm{~B}$ per year, respectively, when compared to the standalone case in which each control area relies only on its local supply resources. This cost saving is equal to $25 \%$ and $22 \%$ of the annual production cost. Including 5\% demand response, the constrained solution decreases the annual production cost by $\$ 10.70 \mathrm{~B}$, while increases the annual surplus by $\$ 9.32 \mathrm{~B}$ in comparison to the standalone case.
\end{abstract}

\footnotetext{
${ }^{*}$ Corresponding author: behboodi@uvic.ca
} 


\section{Keywords}

Demand response, energy market, renewable intermittency, resource allocation, western interconnection

\section{Nomenclature}

$\begin{array}{ll}A & \text { Market state solution matrix } \\ b & \text { Market condition vector } \\ d & \text { Demand curve slope, in } \$ / \text { MWh.MW) } \\ e & \text { Net export, in MW } \\ f & \text { Transfer flow, in MW } \\ p & \text { Price, in } \$ / \text { MWh } \\ p_{\max } & \text { Must-serve load price, in } \$ / \text { MWh } \\ p_{\min } & \text { Must-take generation price, in } \$ / \text { MWh } \\ q & \text { Quantity, in MW } \\ s & \text { Supply curve slope, in } \$ /(\text { MWh.MW }) \\ x & \text { Market state vector } \\ Y & \text { Connectivity matrix } \\ \alpha & \text { Degree of demand inelasticity } \\ \Delta & \text { Difference operator } \\ \omega & \text { Combined demand and supply slope, in } \$ /(\text { MWh.MW) } \\ \Omega & \text { Diagonal matrix of combined slopes } \\ \text { Subscripts } & \\ 0 & \text { Standalone } \\ c & \text { Clearing } \\ d & \text { Demand } \\ p & \text { Price } \\ q & \text { Quantity }\end{array}$




$\begin{array}{ll}r & \text { Responsive } \\ s & \text { Supply } \\ u & \text { Unresponsive } \\ w & \text { Must-take }\end{array}$

\section{Introduction}

Most jurisdictions in North America have adopted renewable energy portfolio policies as part of efforts to reduce greenhouse gas emissions. The inherent intermittency of renewables is the main challenge to the large-scale integration of these clean resources at high penetration levels. The traditional utility approach to generation variability is to operate reserve units, which are usually more costly and may increase emissions. Demand response is a zero-emission and potentially lower-cost alternative to the use of generation reserves. It also benefits the flexible load through payment for their services, and benefits all consumers through lowered electricity costs. The US Department of Energy has adopted a definition of demand response that is now widely recognized for its inclusiveness [1]: "load variations in response to changes in both financial incentives and/or reliability signals over time".

The idea of including demand response in electricity markets is discussed in a large body of recent works. The impact of demand response integration on peak energy consumption, energy price and emissions under load uncertainty is analyzed in [2]. A model of demand response participation in real-time markets to minimize the operation cost considering the load elasticity is formulated in [3]. The interaction between renewable intermittency and demand response in the market environment is investigated in [4].

Load fluctuations and renewable generation intermittency are generally not strongly correlated with each other over a large interconnected system that includes multiple balancing authorities [5]. As a result, the combined interconnection power fluctuations are smaller than the sum of the variations in individual balancing authorities. Neighbouring jurisdictions can take advantage of the geographical diversity of renewable resources within the system, and cooperate more effectively to mitigate the intermittency of renewable power generation. This cooperation, which is beneficial from both reliability and economic viewpoints, requires an enhanced transmission system, sometimes referred to as a "supergrid" [6]. A recent study of consolidation of balancing authorities in the US [7] showed that if planners moved away from a regionally divided electricity system to a national system using high-voltage direct-current transmission lines then the deployment of wind 
and solar power could reduce $\mathrm{CO}_{2}$ emissions by up to $80 \%$ relative to 1990 levels, without an increase in electricity price.

Resource scheduling using locational marginal price (LMP) has been the foundation of modern electricity system operations since the early 1980s when it was first introduced [8]. The basic LMP solution was subsequently extended to perform security constrained economic dispatch (SCED) to satisfy operational constraints. This family of solutions has been deployed very successfully by transmission system operators [9]. However, the LMP formulation considers load to be essentially inelastic. Approaches to compensating demand response that allow consideration of price sensitive loads have been examined [10]. For policy-makers seeking to study the widespread development of renewable resources and the impact of demand response in system operation, the preferred LMP/SCED solution to the resource scheduling problem presents a significant barrier to adoption because the system models are typically constructed in a manner that assumes: (i) the system operation is dominated by supply resources with significant and relatively consistent fixed and variable cost components throughout an interconnected system, and (ii) demand is essentially inelastic and predictable. Solutions to the demand response problem include those proposed by the US Federal Energy Regulatory Commission [11]. Unfortunately, renewable resources such as wind and solar do not fulfill assumption (i), and short-term redispatchable demand does not conform well to assumption (ii).

A deep understanding of the interconnection-scale impact of demand response integration is difficult to achieve in the absence of accurate resource allocation models that properly consider the system-wide impact of demand response on locational energy price calculations and generation resource allocation. This is even more important for the case of large interconnected systems where mixed pricing mechanisms are extant, such as in the Western Electricity Coordinating Council (WECC). In the WECC some regions have fully developed energy markets and others do not, and multiple balancing authorities operate and interact through a myriad of bilateral contracts and other financial arrangements including some as obscure as the Columbia River Treaty [12]. In an effort to address these barriers and to study optimal operation of large-scale interconnections, we are motivated to find a more flexible and general model of the resource scheduling problem based on energy pricing. In the absence of price sensitive loads, the problem of unit commitment is to determine the hourly generation schedule in a way that minimizes the operational costs, which equivalently maximizes the economic surplus (social welfare) [13, 14]. Therefore solving the traditional LMP problem is sufficient. However, when a significant amount of price 
sensitive loads is present, minimizing cost is no longer a satisfactory objective, and maximizing surplus is preferred [15], as described in Section 2. Surplus maximization for the unit commitment problem has been already formulated at the balancing authority level $[16,17,18]$. In the present work, we are interested in analyzing this problem at the interconnection level. More precisely, we seek a set of inter-area power transfers that maximizes the global surplus, which is defined as the sum of consumer and producer surpluses over all balancing authorities in an interconnection.

The optimal operation of the interconnection helps utilities produce electricity with a lower cost, integrate more intermittent renewables, and defer or cancel costly investments in grid infrastructure. Previous work [19] has shown the potential annual savings in production cost due to consolidation of balancing authorities ranges from $2.4 \%$ to $3.2 \%$, considering transmission congestions. The full coppersheet consolidation of the WECC system provides an additional $1.4 \%$ improvement. However this study did not consider the impact of demand response on system resource allocation. Load management assists the WECC system operators in dealing with uncertainty in demand and intermittent resource output [20].

We consider one important reference to be the inelastic demand scenario in which the WECC system as a whole is operated in the most economically efficient manner. This scenario is unlikely because of various jurisdictional regulations, but it does provide an upper bound for the achievable systemwide economic benefits considering the transmission constraints. Thus, demand response with different penetration levels across the system, and potential surplus increases are evaluated with respect to this best achievable performance absent demand response. It should be noted that the outcome of this work is a model to study system-wide scenarios for planning rather than proposing an operational tool to be used in WECC.

Energy scheduling and reserve scheduling can be performed simultaneously to achieve a more economically-efficient use of both supply and demand resources, particularly when reserve sharing is anticipated to be significant $[21,22]$. We exclude reserve scheduling in this formulation/simulation for simplicity. But we recognize that including it is an essential future work.

The new contributions of this work are: (i) a new resource allocation method that incorporates the market-driven demand response into the unit commitment problem; (ii) a new model of the interchange export/import scheduling problem for the global (interconnection-wide) surplus maximization objective; and (iii) a demonstration of the proposed model on the Western Interconnection for the planning year 2024. In Section 2 an overview on the double auction market theory is provided, and in Section 3 the schedul- 
ing problem considering demand price responsiveness is formulated. In Section 4, a reduced model of the WECC system is presented, and in Section 5, simulation results are discussed.

\section{Electricity Markets}

The ultimate purpose of the proposed model of resource allocation is to determine the hourly schedule for the most economically efficient mix of supply and demand resources that does not violate the transfer constraints on system interties within an interconnection. This hourly schedule is essential to establishing the intra-hourly control reference for both supply and demand resource dispatch, which is needed to evaluate the performance of short-term demand response control strategies. To obtain this schedule, an hour-by-hour virtual double auction wholesale market is assigned to each of the system's control areas in which both supply and demand resources participate. Although the magnitude of the responsive load is relatively small, it is still worth considering its impact on the optimal schedule, particularly in the presence of substantial intermittent renewable resources. One key advantage of using the proposed model is that it facilitates modeling of inter-temporal effects such as demand response by load shifting and recovery after load curtailment.

\subsection{Market clearing process}

We begin by considering how prices and quantities are computed in an area. In general, both supply and demand curves are composed of a series of linear segments (sell or buy bidding quantities/prices). For simplicity, we assume supply curves only include a flat segment for non-dispatchable generators (e.g. wind and nuclear power) and a variant segment for dispatchable generators. Similarly, we assume demand curves consist of a flat segment for must-serve loads and a variant segment for deferrable loads (e.g. electric vehicles). The supply and demand curves are given as:

$$
p_{s}=\left\{\begin{array}{lc}
s\left(q_{s}-q_{w}\right)+p_{\min } & q_{s}>q_{w} \\
p_{\min } & \text { otherwise }
\end{array}\right.
$$

and

$$
p_{d}=\left\{\begin{array}{lc}
d\left(q_{d}-q_{u}\right)+p_{\max } & q_{d}>q_{u} \\
p_{\max } & \text { otherwise }
\end{array}\right.
$$

respectively, where $p_{s}$ is the supply price, $s>0$ is the slope of the supply curve, $q_{s}$ is the supply quantity, $q_{w}$ is must-take (non-dispatchable) generation, $p_{\min }$ is the must-take price, $p_{d}$ is the demand price, $d<0$ is the 


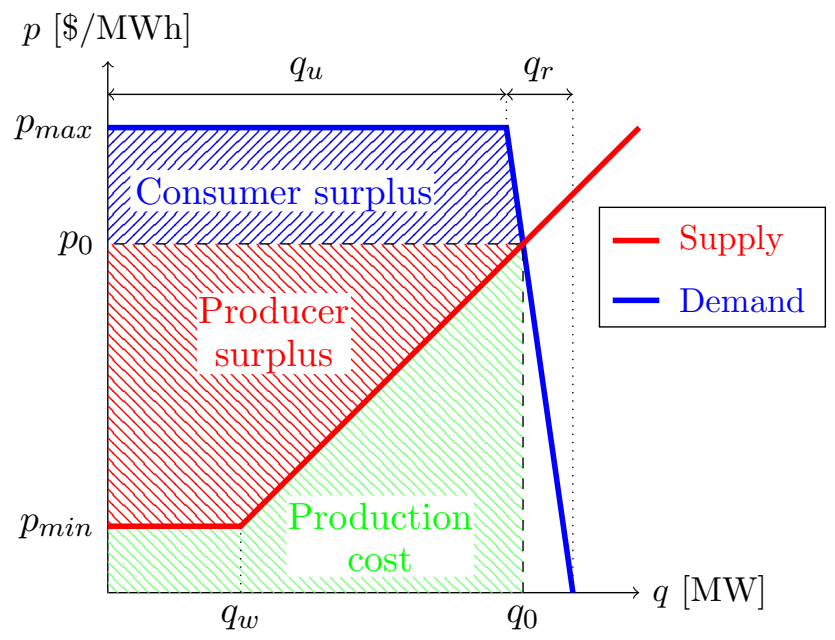

Fig. 1: A double auction electricity market.

slope of the demand curve, $q_{d}$ is the demand quantity, $q_{u}$ is must-serve load, and $p_{\max }$ is the must-serve price. The slope of an inelastic demand curve is infinite $(d \rightarrow-\infty)$. Supply and demand curves are illustrated in Fig. 1.

The supply and demand prices, $p_{s}$ and $p_{d}$ respectively, of energy as well as the supply and demand quantities, $q_{s}$ and $q_{d}$ respectively, of power must satisfy the linear system:

$$
\mathbf{A x}=\mathbf{b},
$$

where the matrix $\mathbf{A}$ represents the area supply and demand, the vector $\mathbf{x}$ represents the prices and quantities for supply and demand, and the vector b represents the solution condition. In the case of the simple linear supply and demand system above, we have:

$$
\mathbf{A}=\left[\begin{array}{cccc}
-d & 1 & 0 & 0 \\
0 & 0 & -s & 1 \\
-1 & 0 & 1 & 0 \\
0 & -1 & 0 & 1
\end{array}\right], \quad \mathbf{x}=\left[\begin{array}{c}
q_{d} \\
p_{d} \\
q_{s} \\
p_{s}
\end{array}\right], \text { and } \quad \mathbf{b}=\left[\begin{array}{c}
p_{\max }-d q_{u} \\
p_{\min }-s q_{w} \\
\Delta q \\
\Delta p
\end{array}\right]
$$

where $\Delta q$ is the export (or import if $\Delta q<0$ ) quantity and $\Delta p$ is the price subsidy (or tax if $\Delta p<0$ ). Note that if both $s$ and $d$ are infinite, this formulation is not appropriate.

The solution price and quantity at which supply equals demand in a standalone area (both $\Delta q$ and $\Delta p$ are zero) is found by solving the standalone 
167 where

$$
\mathbf{A}_{q}=\left[\begin{array}{cccc}
-d & 1 & 0 & 0 \\
0 & 0 & -s & 1 \\
1 & 0 & 0 & 0 \\
0 & 0 & 1 & 0
\end{array}\right] \text {, and } \mathbf{b}_{q}=\left[\begin{array}{c}
p_{\max }-d q_{u} \\
p_{\min }-s q_{w} \\
q \\
q
\end{array}\right]
$$
172

$$
\mathbf{x}=\mathbf{A}^{-1} \mathbf{b}_{\Delta q}=\left[\begin{array}{llll}
q_{d} & p & q_{s} & p
\end{array}\right]^{\mathrm{T}},
$$

173 where

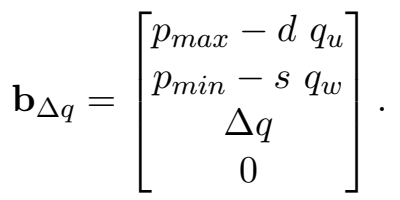

174 In addition, if there is a difference between supply and demand prices 175 such as a renewable subsidy or a carbon tax, the clearing quantity, supply 176 and demand prices can be found by solving the subsidy problem (or tax 
problem for $\Delta p<0)$ :

$$
\mathbf{x}=\mathbf{A}^{-1} \mathbf{b}_{\Delta p}=\left[\begin{array}{llll}
q & p_{d} & q & p_{s}
\end{array}\right]^{\mathrm{T}},
$$

where

$$
\mathbf{b}_{\Delta p}=\left[\begin{array}{cc}
p_{\max }-d & q_{u} \\
p_{\min }-s & q_{w} \\
0 \\
\Delta p
\end{array}\right]
$$

\subsection{Surplus calculation}

The double auction market finds the quantity and price that maximize the total economic surplus, which is geometrically the area between the supply and demand curves, as shown in Fig. 1. By definition, the total surplus is the summation of the producer surplus (the red hatched area) and the consumer surplus (the blue hatched area) [13]. The green hatched area is the electricity production cost.

The idea of global surplus maximization is presented through an example. Consider two control areas with identical demand curves and slightly different supply curves, as illustrated in Fig. 2. The must-take supply resource is $2000 \mathrm{MW}$ in Area $A$, and $1000 \mathrm{MW}$ in Area $B$. If these areas are not connected, their markets will be cleared under the standalone condition as shown in Table 1.

When we consider the unconstrained transfer problem, the generation units in Area $A$ that did not get dispatched when the tieline was not operating are now dispatched to serve additional load in Area $B$. Despite Area $A$, the generation in Area $B$ decreases up to the point where the price difference between two areas is zero as illustrated in Fig. 3. Notice that the clearing price increases in Area $A$ and decreases in Area $B$. As a result, demand quantity decreases in Area $A$ and increases in Area $B$ such that the difference between supply and demand quantities is $500 \mathrm{MW}$ in Area $A$ and -500 MW in Area $B$. Electricity exchange, like any other economic transaction, increases the global surplus (social welfare), as tabulated in Table 2. The maximum global surplus which is obtained under this condition is referred to as the coppersheet solution.

Now we constrain the tieline's transfer capacity to $400 \mathrm{MW}$, which is insufficient to equalize the prices, as illustrated in Fig. 4. Table 3 shows that the global surplus associated with the constrained transfer solution $(\$ 2666 \mathrm{k})$ is between the standalone $(\$ 2643 \mathrm{k})$ and coppersheet surpluses $(\$ 2679 \mathrm{k})$. A surplus-maximizing scheduler identifies the tieline flow such that it either 

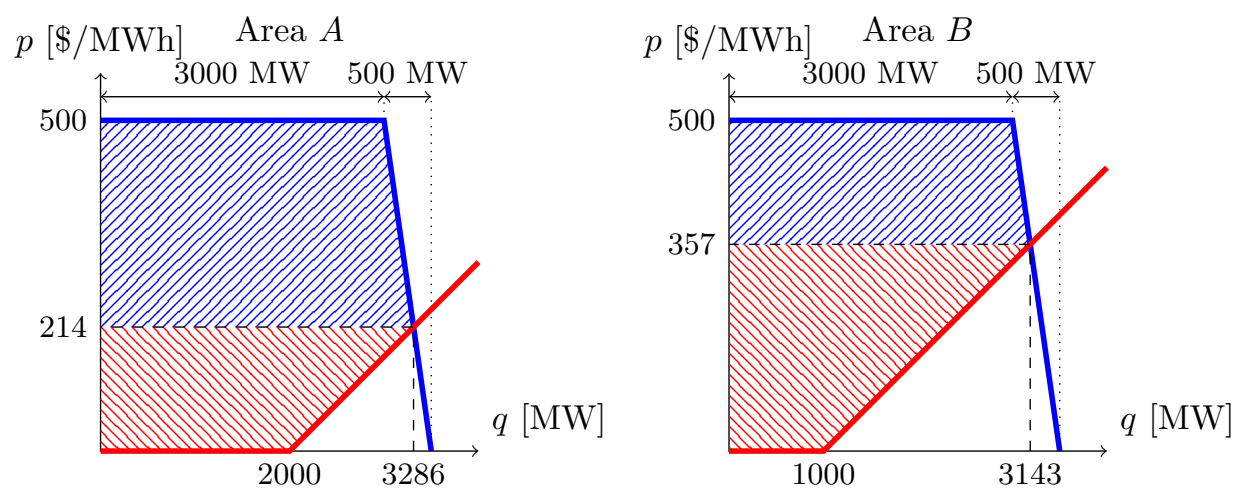

Fig. 2: Standalone markets.
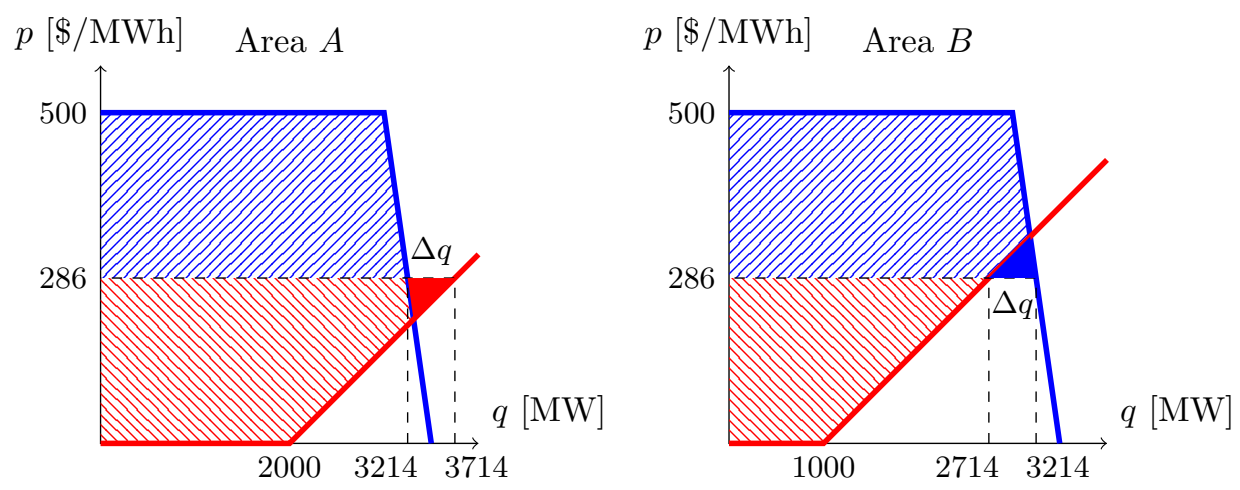

Fig. 3: Interconnected markets with unconstrained transfer capacity.
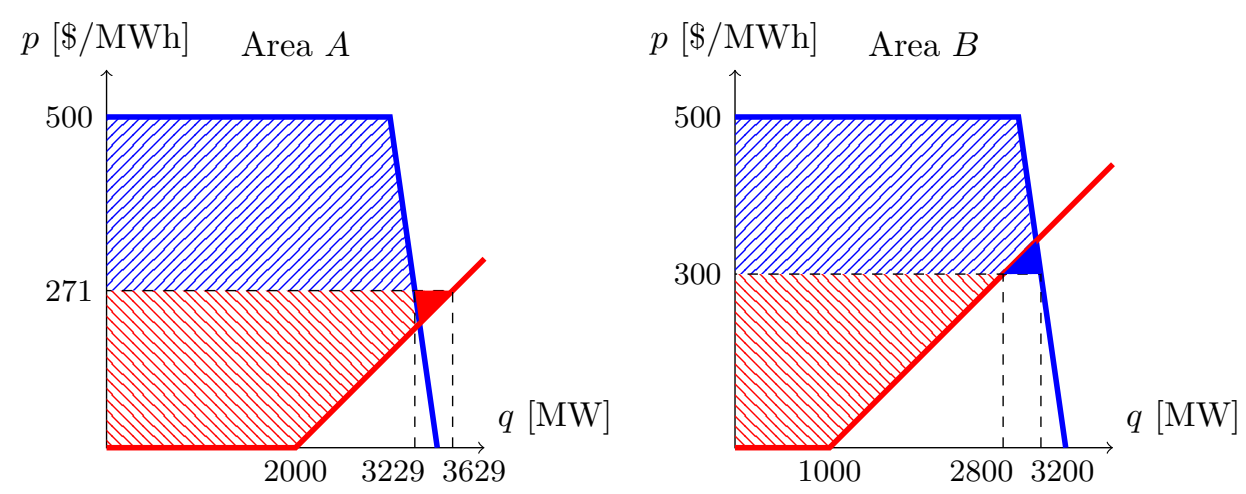

Fig. 4: Interconnected markets with constrained transfer capacity. 
zeros out the price difference or fully utilizes the transfer capacity. This scheduling problem becomes more complex when the number of areas and tielines is increased.

Table 1: Standalone schedule and surplus (zero MW exchange)

\begin{tabular}{|cc|cc|ccc|}
\hline $\begin{array}{c}\text { Control } \\
\text { area }\end{array}$ & $\begin{array}{c}\text { Price } \\
{[\mathbf{\$} / \mathbf{M W h}]}\end{array}$ & $\begin{array}{c}\text { Demand } \\
{[\mathbf{M W}]}\end{array}$ & $\begin{array}{c}\text { Supply } \\
{[\mathbf{M W}]}\end{array}$ & $\begin{array}{c}\text { Consumer } \\
\text { sur. }[\mathbf{k} \mathbf{\$} \mathbf{h}]\end{array}$ & $\begin{array}{c}\text { Producer } \\
\text { sur. }[\mathrm{k} \mathbf{\$} / \mathbf{h}]\end{array}$ & $\begin{array}{c}\text { Total } \\
\text { sur. }[\mathbf{k} \mathbf{\$} / \mathbf{h}]\end{array}$ \\
\hline$A$ & 214 & 3286 & 3286 & 898 & 566 & 1464 \\
$B$ & 375 & 3143 & 3143 & 439 & 740 & 1179 \\
\hline Total & 284 & 6429 & 6429 & 1337 & 1306 & 2643 \\
\hline
\end{tabular}

Table 2: Coppersheet schedule and surplus (500 MW exchange)

\begin{tabular}{|cc|cc|ccc|}
\hline $\begin{array}{c}\text { Control } \\
\text { area }\end{array}$ & $\begin{array}{c}\text { Price } \\
{[\mathbf{\$} / \mathbf{M W h}]}\end{array}$ & $\begin{array}{c}\text { Demand } \\
{[\mathbf{M W}]}\end{array}$ & $\begin{array}{c}\text { Supply } \\
{[\mathbf{M W}]}\end{array}$ & $\begin{array}{c}\text { Consumer } \\
\text { sur. }[\mathbf{k} \mathbf{\$} / \mathbf{h}]\end{array}$ & $\begin{array}{c}\text { Producer } \\
\text { sur. }[\mathbf{k} \boldsymbol{\mathbf { S }} \mathbf{h}]\end{array}$ & $\begin{array}{c}\text { Total } \\
\text { sur. }[\mathbf{k} \mathbf{\$} / \mathbf{h}]\end{array}$ \\
\hline$A$ & 286 & 3214 & 3714 & 666 & 816 & 1482 \\
$B$ & 286 & 3214 & 2714 & 666 & 531 & 1197 \\
\hline Total & 286 & 6428 & 6428 & 1332 & 1347 & 2679 \\
\hline
\end{tabular}

Table 3: Constrained transfer schedule and surplus (400 MW exchange)

\begin{tabular}{|cc|cc|ccc|}
\hline $\begin{array}{c}\text { Control } \\
\text { area }\end{array}$ & $\begin{array}{c}\text { Price } \\
{[\mathbf{\$} / \mathbf{M W h}]}\end{array}$ & $\begin{array}{c}\text { Demand } \\
{[\mathbf{M W}]}\end{array}$ & $\begin{array}{c}\text { Supply } \\
{[\mathbf{M W}]}\end{array}$ & $\begin{array}{c}\text { Consumer } \\
\text { sur. }[\mathbf{k} \mathbf{\$} / \mathbf{h}]\end{array}$ & $\begin{array}{c}\text { Producer } \\
\text { sur. }[\mathbf{k} \boldsymbol{\mathbf { S }} \mathbf{h}]\end{array}$ & $\begin{array}{c}\text { Total } \\
\text { sur. }[\mathbf{k} \mathbf{\mathbf { h }}]\end{array}$ \\
\hline$A$ & 271 & 3629 & 3229 & 713 & 763 & 1476 \\
$B$ & 300 & 2800 & 3200 & 620 & 570 & 1190 \\
\hline Total & 284 & 6429 & 6429 & 1333 & 1333 & 2666 \\
\hline
\end{tabular}

\section{Inter-area Transfer Scheduling}

In this section, we formulate the inter-area transfer scheduling problem, and determine the export/import schedule that maximizes the global surplus excluding and including transmission constraints, i.e., the coppersheet and constrained transfer solutions, respectively.

\subsection{Surplus maximization}

The objective function maximizes the global surplus by varying the local supply and demand dispatch quantities over the interconnection. The optimization effectively aims to maximize the sum of the areas circumscribed by the triangles bounded by the supply and demand curves and the price 
after export/import (see Fig. 3 and Fig. 4). Because the standalone surplus is invariant, it can be ignored in the formulation for surplus maximization. The optimization problem for an $N$-control area system is stated as:

$$
\max _{q_{s_{n}}, q_{d_{n}}} \sum_{n=1}^{N} \frac{1}{2}\left(p_{c_{n}}-p_{0_{n}}\right)\left(q_{s_{n}}-q_{d_{n}}\right),
$$

subject to:

$$
q_{u_{n}} \leq q_{d_{n}} \leq q_{u_{n}}+q_{r_{n}} .
$$

Note that supply and demand constraints are not needed because they are fully captured by the supply and demand curves. The objective function can be simplified to (see Appendix 1):

$$
\min \frac{1}{2} \sum_{n=1}^{N} \omega_{n} e_{n}^{2}
$$

where $e_{n}$ is the difference between the supply and the demand quantities (net export), and $\omega_{n}=\frac{s_{n} d_{n}}{s_{n}-d_{n}}$ is the combined demand and supply slope in area $n$.

Negative prices are allowed in the optimization, but the surplus calculation is modified whenever the clearing price before power exchange $\left(p_{0}\right)$ or after $\left(p_{c}\right)$ is negative. As illustrated in Fig. 5, the positive-price region (red area) is considered as the true surplus increase, excluding the negativeprice region (yellow area). If the standalone price is negative in an area (left side market), as long as the export cannot push the clearing price beyond $0 \$ / \mathrm{MWh}$, the producer surplus is zero, and the supply quantity equals the maximum demand $\left(q_{u}+q_{r}\right)$ plus the export $(e)$. Notice that the resource allocation is at the hour-ahead scheduling level not at the realtime operation level, thus a situation in which the generation exceeds the required power does not occur so that generators never pay a penalty for over-production simply because they can never be allowed to over-produce. The actual surplus appears beyond $0 \$ / \mathrm{MWh}$, where the supply quantity exceeds the local must-take generation. When the clearing price is negative (right side market), the actual import will be the difference between the maximum demand $\left(q_{u}+q_{r}\right)$ and the local must-take generation $\left(q_{s}\right)$, which happens at $0 \$ / M W h$. Thus, the surplus increase beyond this price is virtual and will never be realized during operation. If both prices are negative, the surplus increase is zero - if an area has too much excess power generation such that after exporting to its neighboring jurisdictions the clearing price 

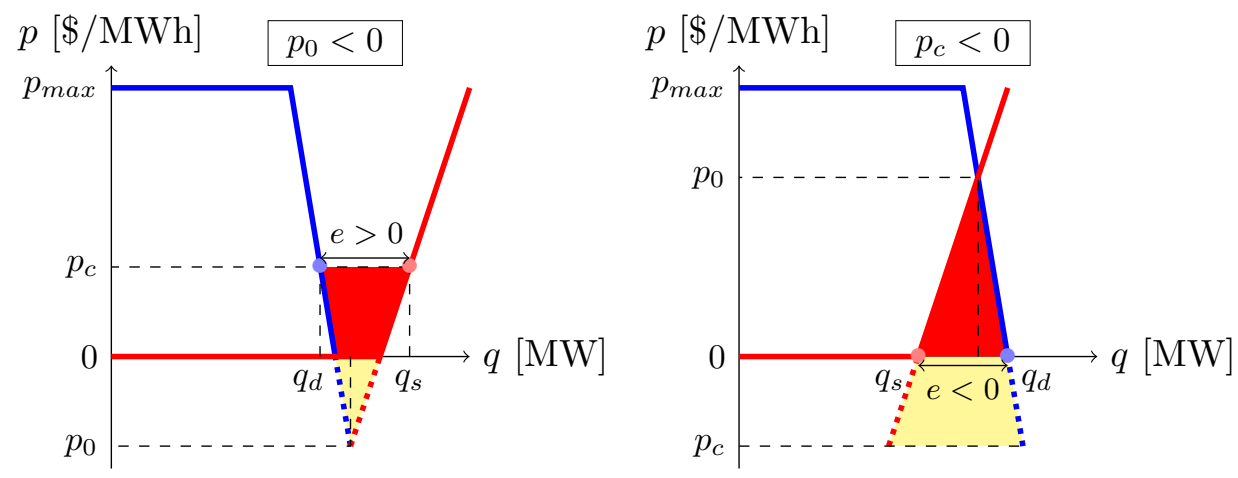

Fig. 5: Surplus calculation with a negative price.

and

$$
\left[\begin{array}{c}
\tilde{q} \\
\tilde{p} \\
\tilde{q} \\
\tilde{p}
\end{array}\right]=\left[\begin{array}{cccc}
-\tilde{d} & 1 & 0 & 0 \\
0 & 0 & -\tilde{s} & 1 \\
-1 & 0 & 1 & 0 \\
0 & -1 & 0 & 1
\end{array}\right]\left[\begin{array}{c}
p_{c a p}-\tilde{d} \sum_{n=1}^{N} q_{u_{n}} \\
\tilde{s} \sum_{n=1}^{N} q_{w_{n}} \\
0 \\
0
\end{array}\right]
$$

$$
\tilde{s}=\left(\sum_{n=1}^{N} s_{n}^{-1}\right)^{-1},
$$

$$
\tilde{d}=\left(\sum_{n=1}^{N} d_{n}^{-1}\right)^{-1},
$$
respectively. We assume the must-take and must-serve prices are the same everywhere, e.g., the minimum price of zero and the maximum price of the 
market cap. With the coppersheet price we obtain the ideal net exports, $\tilde{\mathbf{e}}=\left[\begin{array}{lll}\tilde{e}_{1} & \cdots & \tilde{e}_{n}\end{array}\right]^{\mathrm{T}}$, from Eq. (5a).

We can find the unconstrained transfer flow solution using the graph theory framework. The connectivity matrix for an $N$-area $L$-line interconnection is:

$$
\mathbf{Y}=\left[\begin{array}{ccc}
y_{(1,1)} & \cdots & y_{(1, L)} \\
\vdots & \ddots & \vdots \\
y_{(N, 1)} & \cdots & y_{(N, L)}
\end{array}\right]
$$

where the value for a line $l$ from area $n$ to area $m$ is $y_{(n, l)}=+1$ when $n<m$ and $y_{(n, l)}=-1$ when $n>m$, and $y_{(n, l)}=0$ when $n=m$ or no line connects areas $n$ and $m$. Given the matrix $\mathbf{Y}$ and the ideal net export set $\tilde{\mathbf{e}}$ we can solve for the unconstrained flows on the $L$ lines:

$$
\tilde{\mathbf{f}}=\mathbf{Y}^{+} \tilde{\mathbf{e}}=\left[\begin{array}{lll}
\tilde{f}_{1} & \cdots & \tilde{f}_{L}
\end{array}\right]^{\mathrm{T}}
$$

where $\mathbf{Y}^{+}$is the Penrose pseudo-inverse of $\mathbf{Y}$. Among the possible flow solutions that result in the ideal net exports, this solution has the smallest 2-norm [23], so arguably the transmission loss is minimum if tielines have similar loss factors.

\subsection{Constrained-transfer solution}

As described above, the maximum global surplus is achieved under a condition when the exports are those obtained from the coppersheet solution. This solution may assign a flow to a tieline over its transfer limit. In this case, we seek a flow set that does not violate transmission constraints but still results in the ideal net export values. If such a flow set does not exist, we will seek the flow set that results in a global surplus as close to the maximum surplus as possible. The objective function can be rewritten as:

$$
\min _{\mathbf{e}} \mathbf{e}^{\mathrm{T}} \boldsymbol{\Omega} \mathbf{e}=\min _{\mathbf{f}}(\mathbf{Y} \mathbf{f})^{\mathrm{T}} \boldsymbol{\Omega}(\mathbf{Y} \mathbf{f})
$$

subject to:

$$
\mathbf{f}_{\min } \leq \mathbf{f} \leq \mathbf{f}_{\max }
$$

where $\Omega$ is the $N \times N$ diagonal matrix of $\left[\begin{array}{lll}\omega_{1} & \cdots & \omega_{N}\end{array}\right]$. In any feasible solution, as long as there is a price gradient on a tieline its associated transfer flow equals its limit:

$$
f_{n \rightarrow m}= \begin{cases}f_{n \rightarrow m_{\min }} & \text { for } \quad p_{m}<p_{n} \\ f_{n \rightarrow m_{\max }} & \text { for } \quad p_{m}>p_{n} .\end{cases}
$$


The price gradient vector $\boldsymbol{\delta} \mathbf{p}$ is obtained from:

$$
\delta \mathbf{p}=-\mathbf{Y}^{\mathrm{T}} \mathbf{p}
$$

where $\mathbf{p}$ is the price vector, calculated from (see Appendix 1):

$$
\mathbf{p}=\mathbf{p}_{0}-\Omega \mathbf{e}=\mathbf{p}_{0}-\Omega \mathbf{Y} \mathbf{f} .
$$

We use a sequential quadratic programming (SQP) method [24] implemented by Matlab's optimization toolbox function fmincon [25] to solve this optimization problem and determine the optimum flow set. The objective function is convex, and also the objective and constraints are differentiable functions, thus the solution to the optimization is the global optimum [26]. Perhaps a good initial point to feed into the solver is the coppersheet solution with overloaded tielines adjusted to their capacity limits.

\section{Western Interconnection}

In this section, we present an interconnected system model that loosely represents the Western Interconnection. The WECC system extends from Canada to Mexico and includes the provinces of Alberta and British Columbia in Canada, the northern portion of Baja California in Mexico, and all or portions of 14 western US states. As of March 2016, there are 38 control areas (balancing authorities) in the WECC system [27]. California and Alberta are the only regions with full energy markets in the interconnection.

\subsection{Bulk system model}

A 20-area reduced model of the WECC system, illustrated in Fig. 6, is built by combining two or more balancing authorities into one consolidated area. The system interties (groups of transmission lines) are assumed lossless. The intertie transfer limits are given in Appendix 2, estimated from the WECC 2024 common case [28]. In this model, the internal transmission constraints within the control areas are ignored, although area demand is scaled up by a constant factor that approximately accounts for these losses. The peak load and annual energy consumption forecasts as well as the internal loss factors are provided in Table 4, extracted from the WECC 2024 common case [28]. Intermittent (wind, solar and run-of-river hydro), base and dispatchable generation capacities are given in Table 5 also from the WECC 2024 common case. 


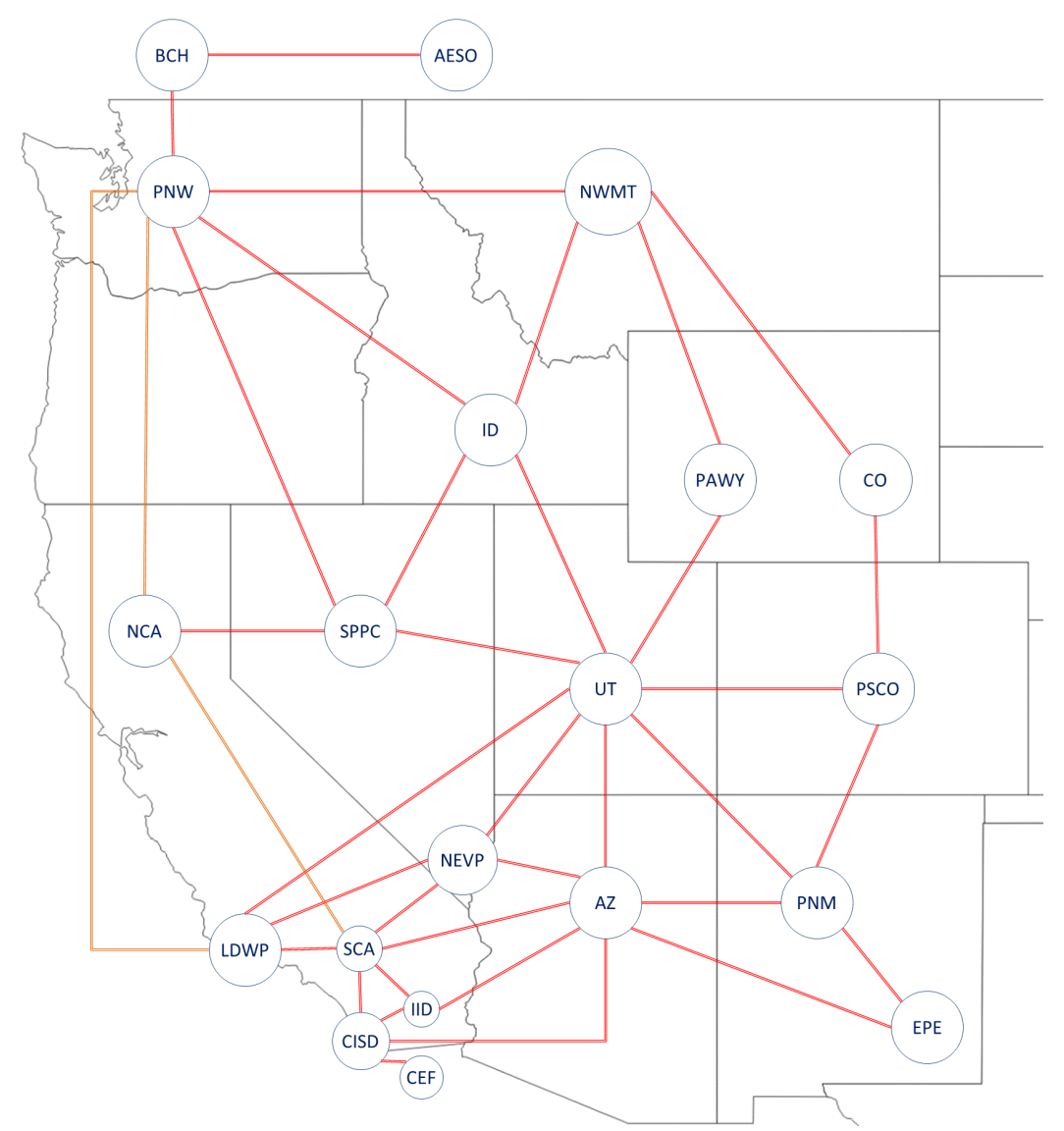

Fig. 6: The bubble pipeline view of the 20-consolidated area WECC model.

\subsection{Market model}

We assign a hypothetical market to every consolidated area. The supply curve consists of a flat segment for must-take generators (wind, solar, run-of-river hydro, biomass, geothermal and nuclear units), and a variant segment for dispatchable generators (coal-fired, hydro and gas-fired units). The hourly power generation of intermittent generation resources (wind, solar and run-of-river) are extracted from the WECC 2024 common case. Once constructed, there is effectively no marginal cost of producing renewable energy, thus it will produce at a price as low $0 \$ / \mathrm{MWh}$. We also assign a price of $0 \$ / \mathrm{MWh}$ to $15 \%$ of hydro capacity, $50 \%$ of coal capacity and all of nuclear capacity so that they will be treated as a must-take resource because once started these generators are costly to shut down and thus exhibit 
Table 4: Demand forecast and internal loss data in 2024

\begin{tabular}{llrrr}
\hline $\begin{array}{l}\text { Area } \\
\text { number }\end{array}$ & Consolidated area & $\begin{array}{r}\text { Peak } \\
{[\mathbf{M W}]}\end{array}$ & $\begin{array}{r}\text { Energy } \\
\text { [GWh/year }]\end{array}$ & $\begin{array}{r}\text { Loss } \\
\text { factor }\end{array}$ \\
\hline \hline 1 & AESO & 16095 & 115061 & 1.019 \\
2 & BCH & 12542 & 69326 & 1.020 \\
3 & PNW = AVA + BPA + CHPD & 33384 & 184103 & 1.025 \\
& + DOPD + GCPD + PACW & & & \\
& + PGE + PSEI + SCL + TPWR & & & \\
4 & NWMT & 1898 & 12163 & 1.023 \\
5 & PAWY & 1681 & 11028 & 1.013 \\
6 & NCA $=$ BANC + CIPB & 30626 & 144848 & 1.043 \\
& + CIPV + TIDC & & & \\
7 & SPPC & 2447 & 15784 & 1.026 \\
8 & ID $=$ IPFE + IPMV + IPTV & 4157 & 19290 & 1.036 \\
9 & UT = PAID + PAUT & 8443 & 39362 & 1.028 \\
10 & CO $=$ WACM + WAUW & 5867 & 34863 & 1.023 \\
11 & LDWP & 7789 & 34129 & 1.027 \\
12 & NEVP & 7034 & 30083 & 1.045 \\
13 & PSCO & 8130 & 41027 & 1.028 \\
14 & SCA $=$ CISC + VEA & 26847 & 119573 & 1.040 \\
15 & AZ $=$ AZPS + SRP & 23596 & 109534 & 1.026 \\
& + TEPC + WALC & & & \\
16 & CISD & 5573 & 26702 & 1.037 \\
17 & IID & 1342 & 4836 & 1.043 \\
18 & PNM & 3136 & 16449 & 1.026 \\
19 & CEF & 3255 & 15452 & 1.033 \\
20 & EPE & 2391 & 11106 & 1.032 \\
\hline
\end{tabular}

a negative marginal cost of operation below these levels.

For simplicity we assume that the variant segment is linear, and the bidding prices of the cheapest and most expensive dispatchable units are the same as the must-take (zero) and must-serve (here $500 \$ / \mathrm{MWh}$ ) prices, respectively. Note that must-take units operate continuously (except during curtailment hours) so their start-up and shut-down costs are not considered. In addition, for simplicity, the start-up and shut-down costs of dispatchable units are not currently considered in the model.

Similarly, the demand curve consists of an unresponsive segment for must-serve loads and a responsive segment for deferrable loads such as water heaters, electric vehicles, heating, ventilation and air conditioning loads. The responsive load can respond to the market price such that it is zero when price is at the market cap, and is all-in when price is zero. A simple demand 
Table 5: Supply data (aggregated installed capacity) in 2024

\begin{tabular}{lrr|r}
\hline & \multicolumn{2}{c}{ Non-dispatchable (must-take) generation } & Dispatchable \\
Area & Intermittent & [MW] & Base (invariable) \\
{$[\mathbf{M W}]$} & generation $[\mathbf{M W}]$ \\
\hline \hline AESO & 2275.2 & 3710 & 17733 \\
BCH & 815.3 & 3531 & 17000 \\
PNW & 14432.0 & 5845 & 36675 \\
NWMT & 664.2 & 1227 & 1993 \\
PAWY & 1315.3 & 1648 & 2105 \\
NCA & 5092.7 & 5351 & 38684 \\
SPPC & 800.0 & 1118 & 3287 \\
ID & 660.3 & 374 & 2845 \\
UT & 256.5 & 2183 & 8136 \\
CO & 656.4 & 1807 & 4310 \\
LDWP & 687.0 & 89 & 8727 \\
NEVP & 75.7 & 426 & 13085 \\
PSCO & 2441.1 & 1616 & 11645 \\
SCA & 6028.1 & 977 & 28645 \\
AZ & 3220.6 & 8601 & 39353 \\
CISD & 432.8 & 34 & 8558 \\
IID & 34.4 & 1170 & 1514 \\
PNM & 840.3 & 910 & 4504 \\
CFE & 384.2 & 697 & 6600 \\
EPE & 1.3 & 0 & 3512 \\
\hline
\end{tabular}

model is developed to obtain the hourly responsive load function. Given that the wide variety of demand response functions available in literature can all be linearized in the neighborhood of the operating point, a linear model of demand is chosen for the multi-area resource allocation focus of this study.

The hourly demand forecast $q_{h}$ in every balancing authority is available in the WECC 2024 common case. A portion of $q_{h}$ is flexible and potentially responsive to the market price, and the remainder is unresponsive. For simplicity, we assume the relative magnitude of the unresponsive portion, $\alpha=\frac{q_{u}}{q_{h}}$, remains constant over the entire year. To approximate the responsive demand, we make the additional assumption that responsive load is linearly sensitive to the price fluctuation in a 4-hour future time window. If the average of inelastic-demand clearing prices over a 4-hour future time window (from a 4-hour ahead forecast) is less than the inelastic-demand clearing price at a given hour, then the cleared elastic demand will be lower than the inelastic demand. The motivation behind this behavior is driven by the opportunity to postpone a proportion of responsive load in order to 
take advantage of lower prices within the next 4 hours.

Consider $\bar{p}$ is the price at which the cleared quantity of the elastic and inelastic demands are equal. We assume $\bar{p}$ is equal to the average of estimated inelastic-demand clearing prices in a 4-hour future time window. If the hourly price is equal to the average price, there is no economic incentive to adjust flexible loads. Using a linear demand curve, the maximum responsive load is:

$$
q_{r}=\frac{(1-\alpha) p_{c a p}}{p_{c a p}-\bar{p}} q_{h}
$$

Fig. 7 shows an hour at which must-take generation, inelastic demand and the associated price are $1000 \mathrm{MW}, 3250 \mathrm{MW}$ and 321 \$/MWh, respectively. Consider the case for which the forecast shows the must-take generation will increase to $1500 \mathrm{MW}$ after one hour, $2000 \mathrm{MW}$ after two hours and $2500 \mathrm{MW}$ after three hours, therefore the associated prices will be $250 \$ / \mathrm{MWh}, 179 \$ / \mathrm{MWh}$ and $107 \$ / \mathrm{MWh}$, respectively if the demand remains constant. The average price of these four hours is $214 \$ / \mathrm{MWh}$. Assuming $80 \%$ of the demand is inelastic, then according to the model if the hour inelastic-demand price were $214 \$ / \mathrm{MWh}$, the elastic demand quantity would be the same as the inelastic demand quantity (3250 MW). Because the hourly price ( $321 \$ / \mathrm{MWh})$ is greater than the average price, the responsive load adjusts such than the clearing price and cleared quantity are $295(<321) \$ /$ MWh and $3066(<3250)$ MW, respectively. This demand function gives an approximately constant energy consumption model over a 4-hour window.

Although it may seem that a relatively large fraction of the demand is responsive, the active responsive demand is typically a smaller fraction. The dispatched quantity of the responsive demand is implicitly restricted between the quantities associated with the cheapest and the most expensive prices estimated in a 4 hour future time window, not between zero and $q_{r}$. This restriction avoids the load control saturation and oscillation observed in some studies of short-term dispatchable demand response [29, 30, 31].

\section{Results and discussion}

We evaluate the proposed scheduling method on the reduced WECC baseline model for each 8784 hours of the year 2024. First, a simulation is performed assuming the demand is completely inelastic. Second, another simulation is carried out for a case in which $5 \%$ of demand is price sensitive. To set up the responsive demand functions, the 4-hour rolling average prices 

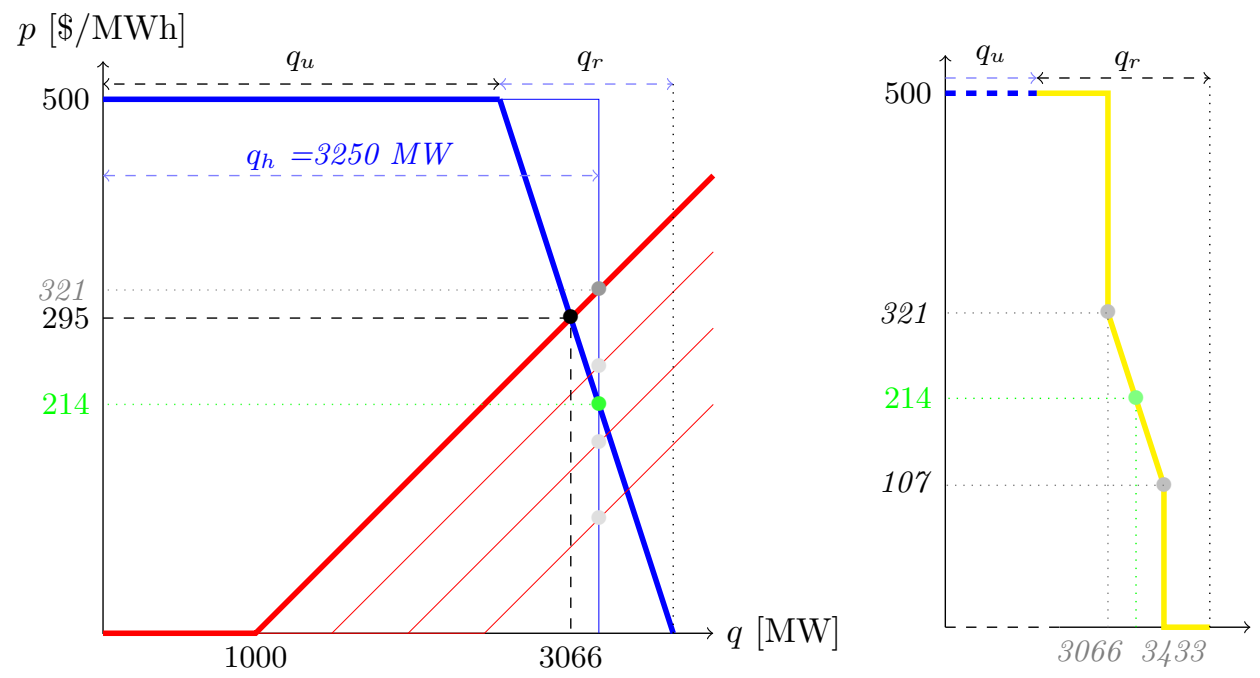

Fig. 7: Responsive load shape example.

(in each area) are gathered from the first simulation and used in the second one. All presented figures are from the second simulation with the transfer constraint limits set to $75 \%$ of the rated transfer capacity. Finally, several simulations are performed to explore the impact of various levels of demand response, and of relaxation of the transfer constraint limit on global cost.

\subsection{Inelastic demand}

The simulation results, excluding demand response, show that the unconstrained and the constrained transfer solutions decrease the global electricity production cost (and correspondingly increase the global surplus) by $\$ 12.30 \mathrm{~B}$ and $\$ 10.67 \mathrm{~B}$ per year, respectively, when compared with the standalone condition case. This cost reduction is equal to $25 \%$ and $22 \%$ of the standalone production cost respectively. The $\$ 12.30 \mathrm{~B}$ reduction is the difference between the two extreme coppersheet and standalone conditions. In WECC and many other jurisdictions, balancing authorities exchange electricity according to long-term and short-term bilateral contracts. Therefore, without the proposed unified operation the production cost is lower than the standalone condition case. In addition, in the model, we assume hydro (up to $15 \%$ of total nominal capacity) and baseload thermal (up to $50 \%$ of total nominal capacity) power plants are treated as must-take resources (base generation) to satisfy operational constraints. Thus, the reported percentage of cost saving, which is the cost reduction divided to the total cost is 
Table 6: Producer cost and surplus reduction for $100 \%$ inelastic demand for 2024 (in $\mathrm{M} \$$ /year)

\begin{tabular}{lrr|rr}
\hline & Producer cost reduction & Producer surplus reduction \\
\hline & Unconstrained & Constrained & Unconstrained & Constrained \\
\hline \hline AESO & 6642 & 1797 & 11421 & 2820 \\
BCH & 55 & 149 & 79 & 284 \\
PNW & 35 & 479 & -552 & 588 \\
NWMT & -260 & -236 & -1622 & -1516 \\
PAWY & -297 & -246 & -2513 & -2132 \\
NCA & -393 & 121 & -817 & 145 \\
SPPC & -297 & -254 & -1058 & -933 \\
ID & 1873 & 1907 & 2630 & 2696 \\
UT & 453 & 557 & 763 & 997 \\
CO & 1244 & 1296 & 2978 & 3147 \\
LDWP & 2304 & 2422 & 2498 & 2632 \\
NEVP & -183 & -4 & -214 & -8 \\
PSCO & -454 & -306 & -1044 & -753 \\
SCA & 5697 & 6083 & 7215 & 7771 \\
AZ & -4624 & -4082 & -12111 & -10968 \\
CISD & 992 & 1108 & 1061 & 1187 \\
IID & -213 & -192 & -1467 & -1375 \\
PNM & -324 & -262 & -873 & -735 \\
CFE & -521 & -287 & -873 & -506 \\
EPE & 573 & 622 & 573 & 622 \\
\hline Total & 12301 & 10671 & 6075 & 3965 \\
\hline
\end{tabular}

over-estimated because its denominator excludes a portion of the operation

Table 6 compares the producer cost reduction and surplus reduction in each consolidated area under unconstrained and constrained solutions. Negative cost reduction indicates an increase in production cost in that area. We note that although the magnitude of the decreased producer surplus is greater than the magnitude of the decreased production cost in many consolidated areas, the magnitude of the total surplus reduction is smaller than the magnitude of the total cost reduction.

\subsection{Elastic demand}

\section{Coppersheet condition}

Fig. 8 illustrates the aggregated hourly demand with $5 \%$ responsive fraction, intermittent generation and base generation (both must-take) in the summer peak month of July and the winter peak month of December 2024. 

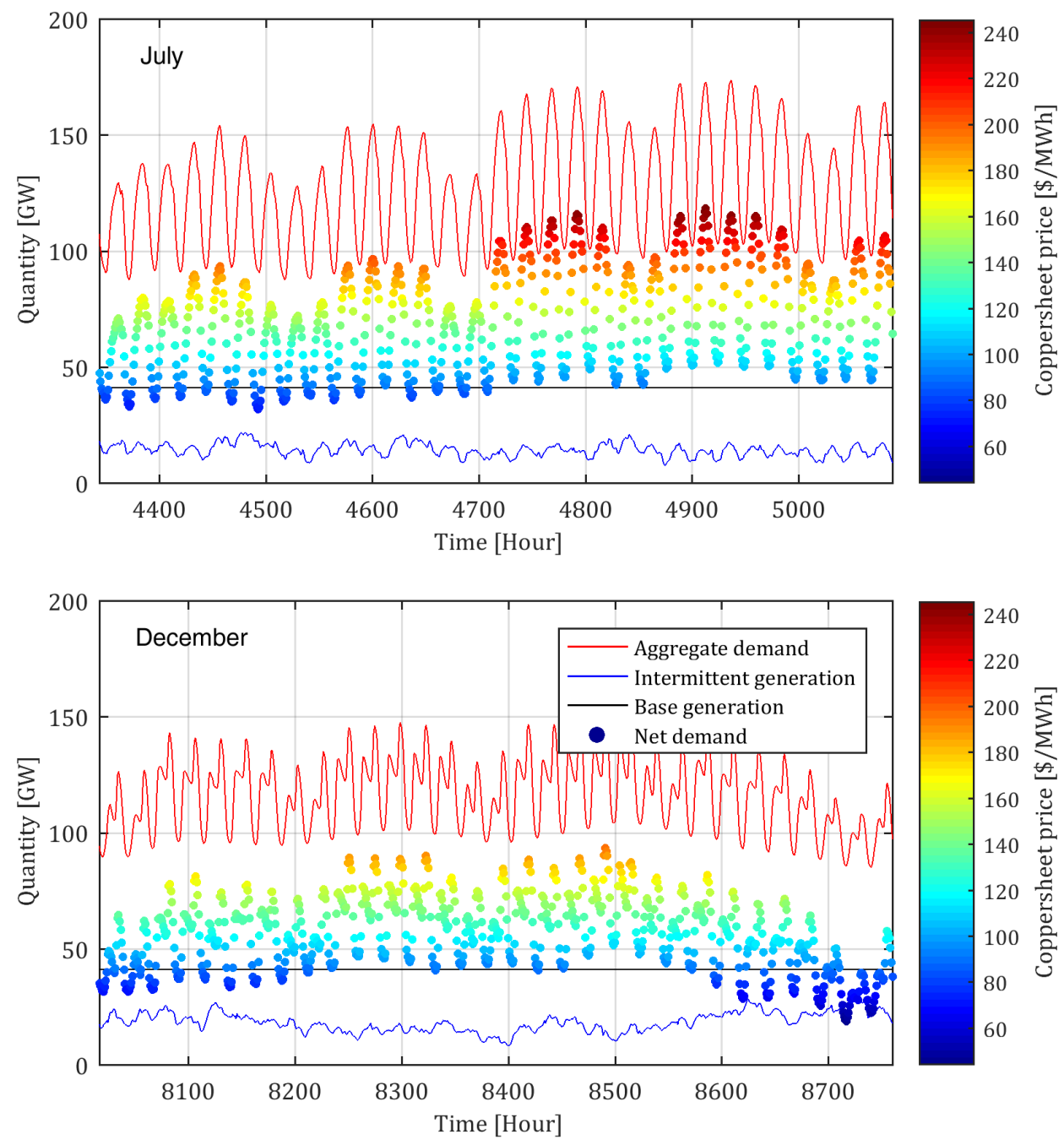

Fig. 8: Coppersheet demand, must-take and associated prices.

432 In addition, the net demand, which is the difference between the aggregated

demand and the must-take generation is illustrated. The color of the net demand represents the associated coppersheet price. Notice that dispatchable generation is also equal to the net demand. As expected, smaller net demand is associated with lower prices.

Fig. 9 shows the maximum global cost reduction (relative to standalone global cost) versus the standard deviation of standalone prices (for each of 


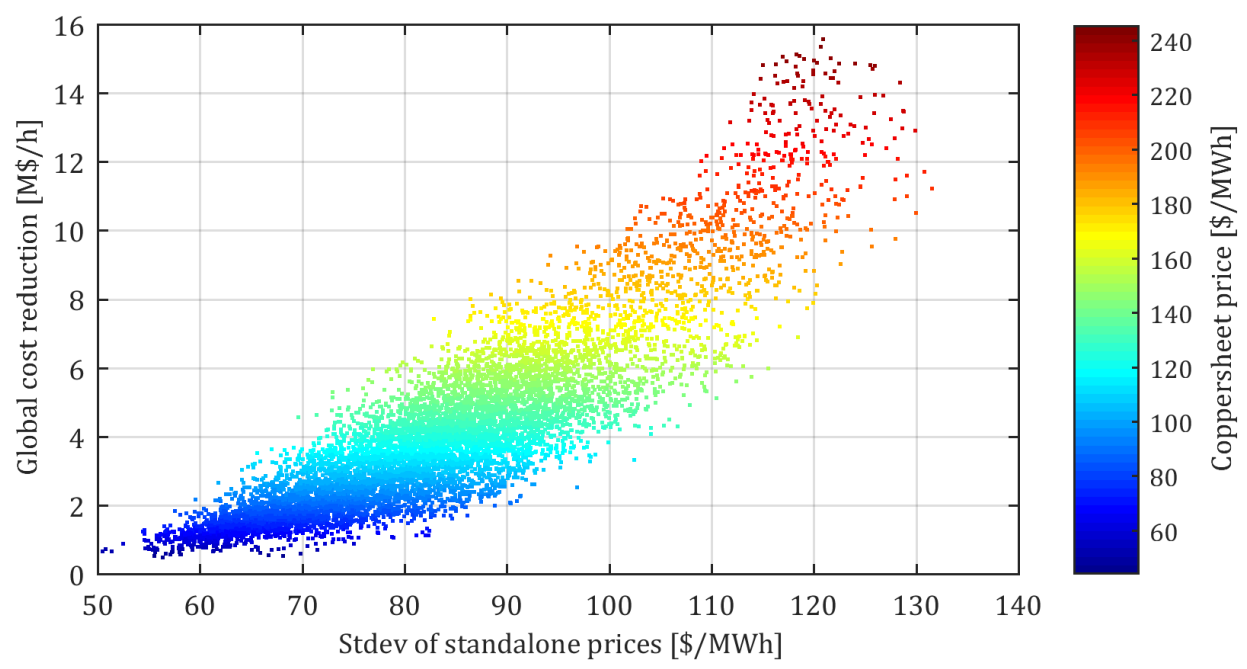

Fig. 9: Global cost reduction vs. standard deviation of standalone prices for each hour.

8784 hours in the year 2024). Negative prices are considered zero when computing the standard deviation. The color represents the associated coppersheet price. A larger standard deviation value indicates a greater resource diversity, which usually creates a greater opportunity to reduce the production cost by exchanging power within the interconnection.

\section{Constrained transfer condition}

Fig. 10 illustrates fluctuations of the hourly global cost reduction under both the unconstrained and the constrained transfer conditions in July and December 2024. Clearly, the cost reduction is strongly correlated with demand. The color represents the economic utilization factor, which is a proposed performance index for the transmission system defines as the ratio of the cost reduction associated with the constrained transfer solution to the cost reduction associated with the unconstrained transfer solution on an hourly basis. We note that there is a greater opportunity to reduce the production cost in December than in July, despite the lower aggregate demand in December. The reason is the magnitude of net demand is more diverse over the system in winter than in summer. In other words, the relatively lower demand in winter enables some areas to feed cheap electricity to the rest of the system, so other areas do not schedule their more expensive units. However, because of transfer constraints the coppersheet 

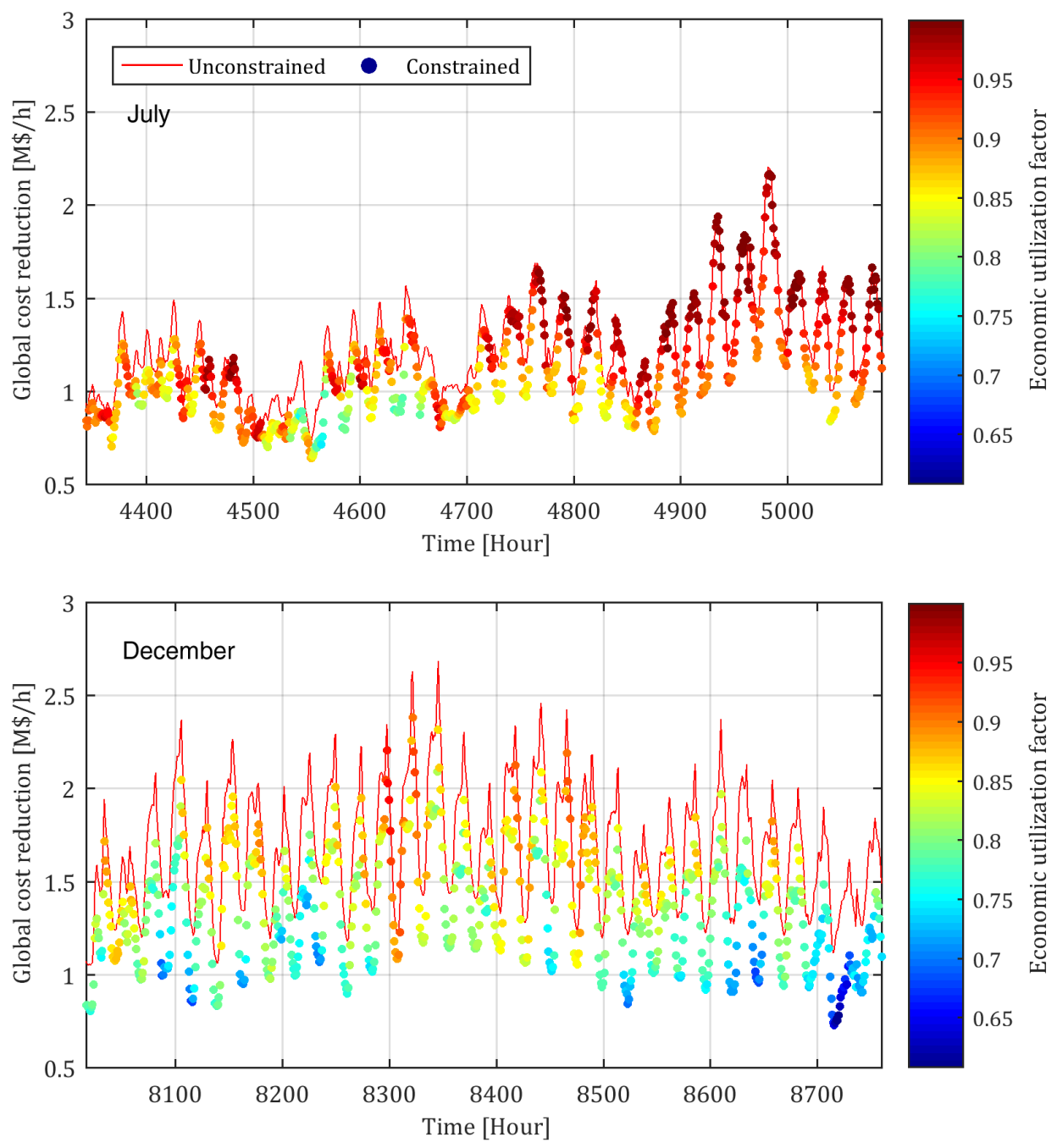

Fig. 10: Global hourly cost reduction.

export/import schedule is not usually achievable in December, thus the economic utilization factor in December is considerably lower than in July.

Fig. 11 shows a set of the "economic utilization factor" and the "standard deviation of clearing price over areas" pairs. The utopia point is at the top left corner, where the clearing price is uniform over the entire interconnection. As the standard deviation approaches zero, the economic utilization factor increases. The color represents the mean value of clearing 


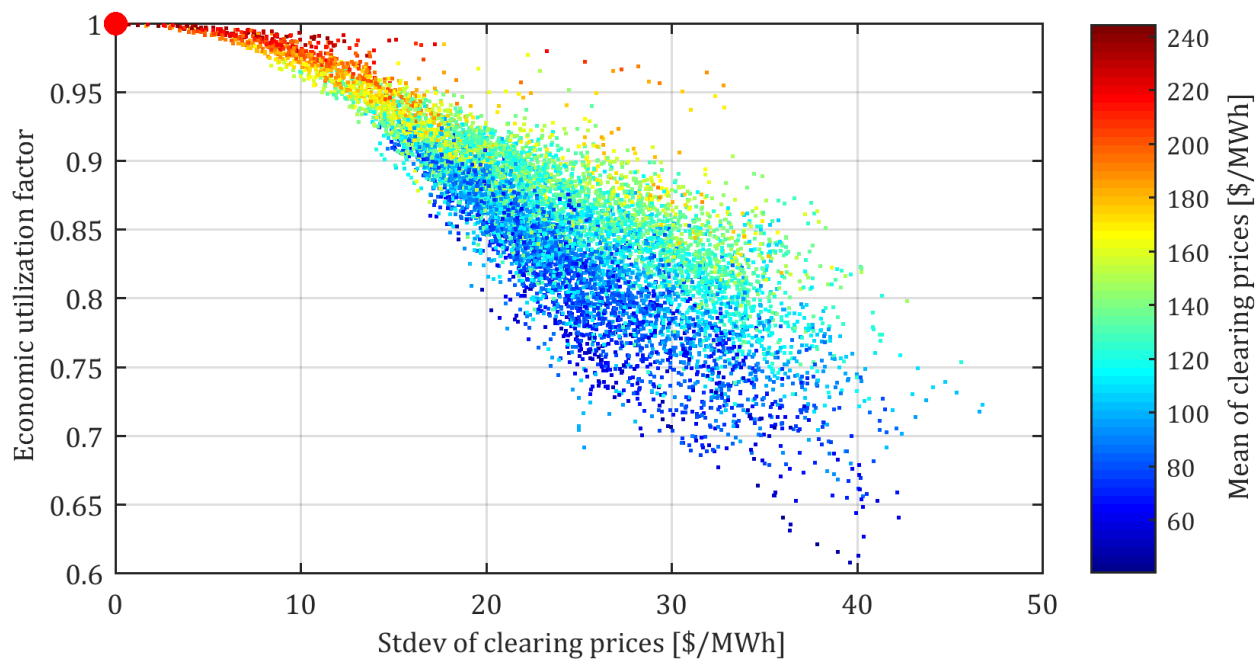

Fig. 11: Economic utilization factor vs. price standard deviation.

prices.

Fig. 12 shows the optimal transfer set at the system peak hour. The node color represents the price associated with the standalone condition case, which varies between $0 \$ / \mathrm{MWh}$ and $500 \$ / \mathrm{MWh}$ with a standard deviation of $124 \$ / \mathrm{MWh}$. Because of the electricity exchange, the clearing price decreases in importing areas and increases in exporting areas. In the peak hour, the clearing price in AESO decreases to $251 \$ / \mathrm{MWh}$, in $\mathrm{BCH}$ and CFE increases to $251 \$ / \mathrm{MWh}$ and $236 \$ / \mathrm{MWh}$ respectively, and in the rest of the system becomes $241 \$ / \mathrm{MWh}$. Consequently, suppliers will gather less surplus in importing and more surplus in exporting areas in comparison to the standalone condition. The magnitude of the decreased surplus in importing areas is greater than the magnitude of increased surplus in exporting areas thus sharing generators decreases the overall producer surplus.

Table 7 compares the production cost per unit associated with the standalone and the constrained transfer solutions in every consolidated area for the $100 \%$ and the $95 \%$ inelastic demand conditions. In general, the production cost per unit decreases in importer-areas, and increases in exporterareas. Table 7 indicates that demand response does not reduce the production cost per unit notably. Without demand response, the average production cost under the standalone and the constrained transfer solutions are $41.96 \$ / \mathrm{MWh}$ and $33.40 \$ / \mathrm{MWh}$, respectively. With $5 \%$ demand response, 


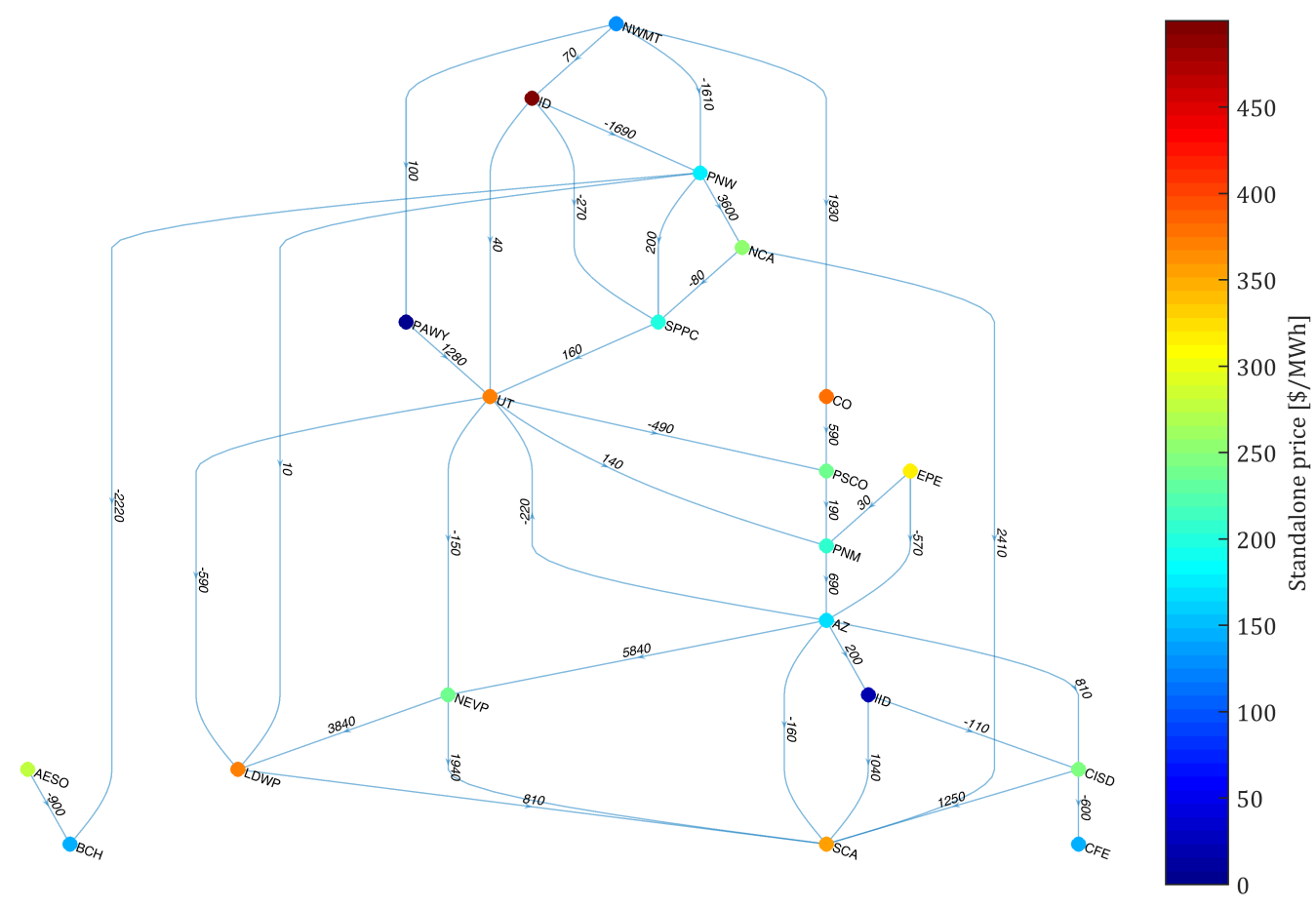

Fig. 12: Optimal transfer flow solution at the system peak hour.

the average production cost under the standalone and the constrained transfer solutions are 41.95\$/MWh and $33.39 \$ / \mathrm{MWh}$, respectively. Notice that the electricity production cost is very low in consolidated areas with a significant amount of must-take generators in some hours.

\subsection{British Columbia}

We now illustrate the impact of optimal scheduling on British Columbia's export/import schedule. British Columbia's hydro-dominated grid connects Alberta's fossil-dominated grid to the rest of the WECC system. Hydroelectric storage assets in British Columbia can also provide the reserves needed to help WECC integrate a significant amount of intermittent renewables in the future.

Fig. 13 illustrates the load duration curve of the Pacific NorthwestBritish Columbia tieline. The color represents the price difference. The positive direction is from Pacific Northwest to British Columbia, with positive price difference as the British Columbia price minus the Pacific Northwest price. The price difference is zero when the transfer flow is not at 
Table 7: Production cost per unit in $\$ / \mathrm{MWh}$

\begin{tabular}{lrr|rr}
\hline \multicolumn{3}{c}{ Standalone } & \multicolumn{2}{c}{ Constrained } \\
\hline \hline AESO & $\mathbf{1 0 0 \%}$ inelastic & $\mathbf{9 5 \%}$ inelastic & 100\% inelastic & $\mathbf{9 5 \%}$ inelastic \\
BCH & 78.48 & 78.47 & 67.51 & 67.50 \\
PNW & 32.72 & 32.71 & 31.31 & 31.30 \\
NWMT & 26.33 & 26.31 & 24.64 & 24.63 \\
PAWY & 1.45 & 1.44 & 14.78 & 14.77 \\
NCA & 0.00 & 0.00 & 11.11 & 11.10 \\
SPPC & 32.14 & 32.13 & 31.68 & 31.67 \\
ID & 9.76 & 9.75 & 21.29 & 21.28 \\
UT & 109.06 & 109.07 & 32.83 & 32.79 \\
CO & 35.66 & 35.62 & 26.92 & 26.91 \\
LDWP & 50.93 & 50.92 & 19.19 & 19.18 \\
NEVP & 97.06 & 97.04 & 51.01 & 51.01 \\
PSCO & 49.45 & 49.44 & 49.91 & 49.90 \\
SCA & 26.24 & 26.23 & 31.62 & 31.61 \\
AZ & 76.38 & 76.37 & 41.27 & 41.26 \\
CISD & 6.11 & 6.11 & 28.10 & 28.09 \\
IID & 79.17 & 79.17 & 52.90 & 52.90 \\
PNM & 0.01 & 0.01 & 13.82 & 13.81 \\
CFE & 16.58 & 16.57 & 27.71 & 27.71 \\
EPE & 21.43 & 21.43 & 33.10 & 33.11 \\
\hline Average & 90.20 & 90.19 & 57.33 & 57.33 \\
\hline
\end{tabular}

its limits, because the neighboring area prices will naturally equilibrate due to the power transfer. As shown, British Columbia exports a significant amount of the imported electricity (820-900 MW) to Alberta. The positive direction of the Alberta-British Columbia tieline is from Alberta to British Columbia, with positive price difference as the British Columbia price minus the Alberta price. The optimal solution suggests that the AlbertaBritish Columbia tieline is usually operated under the full transfer capacity (900 MW), and as a result there is a price gradient on this tieline. Therefore British Columbia has an arbitrage opportunity buying relatively cheaper electricity from the US to sell to Alberta.

Fig. 14 shows the surplus increase as a function of the net export in British Columbia. The shape of this curve should be a parabola according to Eq. (7c), which is verified in the figure. The color represents the clearing price. 


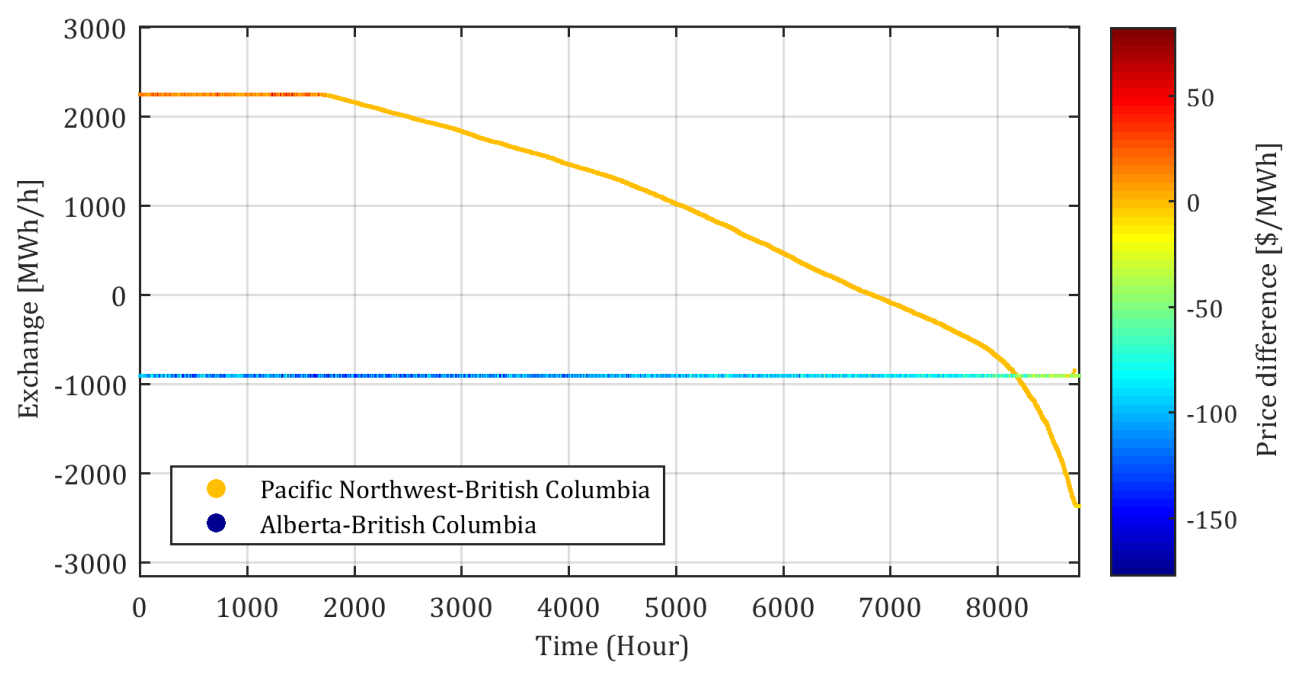

Fig. 13: Load duration curve of the Pacific Northwest-British Columbia and the Alberta-British Columbia tielines.

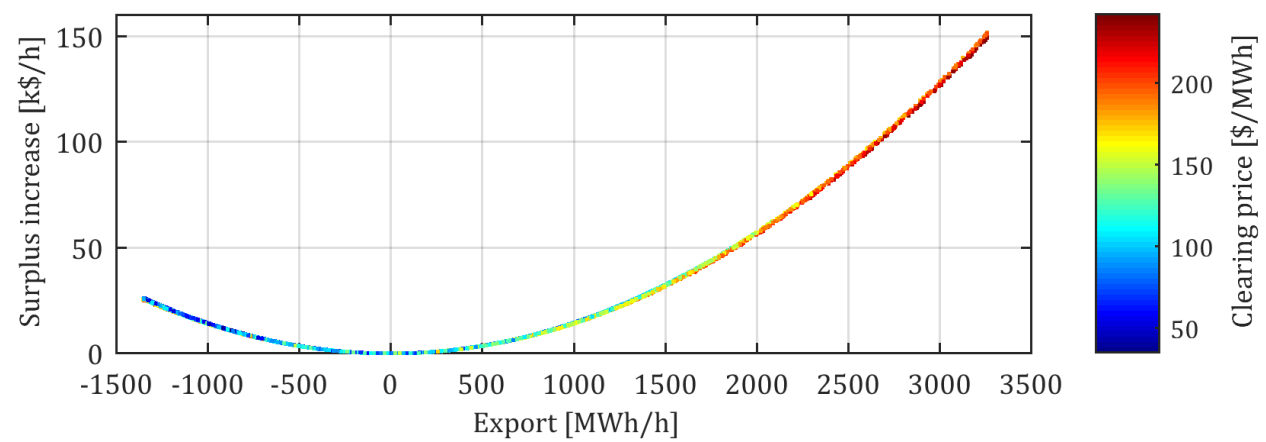

Fig. 14: Surplus increase in British Columbia.

\subsection{Sensitivity analysis}

The model presented belongs to a class of agent-based models for which validation can be challenging [32]. Validation methods include the usual statistical, behavior, and structural validation, as well as so-called face validation in which experts observe the response of the system to various scenarios to consider whether the model exhibits the expected local and global properties and sensitivities. In spite of these challenges, agent-based models are particularly well-suited for the study of transient dynamics in highly complex hybrid econo-physical systems such as smart-grids [33]. If the model 
behaves in the same way as the physics of the problem dictates, the model can be a useful tool that provides insight to the system behavior [34].

For the proposed model we expect that (i) upgrading the transmission system and (ii) integrating demand response result in a greater cost reduction. Table 8 confirms this expectation: as the intertie constraints are relaxed the global cost decreases. The same trend is also observed when the fraction of responsive demand increases significantly. However, the economic benefit of introducting inter-hourly demand response is not substantial when the system is operated with the optimal inter-area transfer set. The rational behind this is that the optimal transfer set has already adjusted to price fluctuations (as much as the transmission system allows); hence the remaining opportunity for demand response to react is very limited. If we used a more flexible demand curve such as that presented in previous studies by the authors $[35,36]$, the impact of demand response would be potentially greater, but probably still not comparable with the impact of the optimal interchange transfer.

Table 8: Global cost reduction

\begin{tabular}{|c|c|c|c|c|}
\hline $\begin{array}{l}\text { Demand } \\
\text { response }\end{array}$ & $\begin{array}{r}75 \% \text { transfer } \\
\text { limit }[\mathrm{B} \$]\end{array}$ & $\begin{array}{r}90 \% \text { transfer } \\
\text { limit }[\mathrm{B} \$]\end{array}$ & $\begin{array}{r}105 \% \text { transfer } \\
\text { limit }[\mathrm{B} \$]\end{array}$ & $\begin{array}{r}\text { Copper- } \\
\text { sheet }[\mathrm{B} \$]\end{array}$ \\
\hline $0 \%$ & 10.67 & 10.85 & 11.01 & 12.30 \\
\hline $1 \%$ & 10.68 & 10.86 & 11.02 & 12.31 \\
\hline $5 \%$ & 10.70 & 10.88 & 11.04 & 12.33 \\
\hline $10 \%$ & 10.72 & 10.91 & 11.06 & 12.35 \\
\hline $20 \%$ & 10.77 & 10.95 & 11.10 & 12.39 \\
\hline $50 \%$ & 10.85 & 11.04 & 11.19 & 12.48 \\
\hline
\end{tabular}

Relaxation of the transfer limit from $75 \%$ to $90 \%$ (even to 105\%) does not provide a significant additional cost reduction, in comparison to the achievable benefit from operating the system under optimal inter-area transfer set (relative to standalone case). Some tielines probably need major upgrades, but most have sufficient transfer capacity at least for the WECC 2024 scenario studied. This finding highlights the great cost reduction opportunity that exists in operating the interconnection in an unified manner with the existing transmission capacity. This opportunity is more appreciable with greater penetration levels of intermittent renewables in the future. Operating the system in an economically efficient manner enables the interconnection to meet its greenhouse gas emissions reduction targets with a relatively moderate incremental cost. Although technical and non-technical barriers make a unified scheduling and dispatch control challenging, distributed dis- 
patch control strategies exist that can provide sub-optimal inter-area transfer sets.

Optimizing the interchange transfer effectively depresses the clearing price by sharing low-cost generation units over the interconnection. Consequently, the expensive peak units are dispatched less frequently and the annual producer surplus decreases. Table 9 indicates the global producer surplus reduction for different limits of transfer constraint and levels of demand response. For example, under the $75 \%$ limit of transfer constraint and $5 \%$ demand response, this reduction is $4 \%$ of the global producer surplus. In general we find that optimal scheduling decreases producer surplus which may have an adverse economic impact both on operators that rely on congestion revenues and zero marginal-cost generation units that must recover capital costs.

Table 9: Global producer surplus reduction

\begin{tabular}{|c|c|c|c|c|}
\hline $\begin{array}{l}\text { Demand } \\
\text { response }\end{array}$ & $\begin{array}{r}75 \% \text { transfer } \\
\text { limit }[\mathrm{B} \$]\end{array}$ & $\begin{array}{r}90 \% \text { transfer } \\
\text { limit }[\mathrm{B} \$]\end{array}$ & $\begin{array}{r}105 \% \text { transfer } \\
\text { limit }[\mathrm{B} \$]\end{array}$ & $\begin{array}{r}\text { Copper- } \\
\text { sheet }[\mathrm{B} \$]\end{array}$ \\
\hline $0 \%$ & 3.96 & 4.07 & 4.26 & 6.07 \\
\hline $1 \%$ & 3.97 & 4.07 & 4.27 & 6.08 \\
\hline $5 \%$ & 4.00 & 4.10 & 4.30 & 6.11 \\
\hline $10 \%$ & 4.03 & 4.13 & 4.33 & 6.14 \\
\hline $20 \%$ & 4.08 & 4.18 & 4.38 & 6.19 \\
\hline $50 \%$ & 4.19 & 4.29 & 4.49 & 6.30 \\
\hline
\end{tabular}

\section{Conclusions}

In this paper we have presented a method to model the limits and optimal generation and demand response allocation for the hourly schedule problem. The purpose is not to solve the interconnection resource allocation problem itself. Rather we seek to provide a method that facilitates impact studies of renewable generation and demand response interaction at the interconnection scale without fully implementing the various market designs extant.

Accordingly a new resource allocation modeling method that incorporates both energy supply and demand response resource is presented. This method is used to model the interconnection-scale scheduling problem in the Western Electricity Coordinating Council (WECC) system planning year 2024. We quantify the potential benefits of demand response integration in WECC using the proposed surplus-maximizing scheduling model considering tieline transfer limits on an hourly basis. The method determines the 
optimal inter-area transfer set that effectively makes the clearing price uniform over the interconnection's markets (as much as possible). The overall consumer surplus increases and the overall producer surplus decreases, while the increased magnitude is always greater than the decreased magnitude. At the same time, the magnitude of production cost decrease is greater than the magnitude of produce surplus decrease. Results show that inter-regional collaboration assist control areas in reducing production cost by $\$ 10.67 \mathrm{~B}$, equal to $22 \%$ relative to the standalone condition with inelastic demand. In addition, integration of $5 \%$ demand response provides an additional $\$ 27 \mathrm{M}$ cost saving. However, we also conclude that economic benefit of inter-hourly demand response is not substantial when the system is operated with the optimal inter-area transfer set, which suggests that the majority of the benefits for demand response arise from intra-hourly demand response resources which are not considered in conventional hourly resource scheduling mechanisms.

The hourly supply and demand resource commitments found in this paper can be used to establish a 5-minute redispatch market in each balancing authority to provide reliable and efficient short-term matching of generation and load resources. Suitable control systems are needed to enable demand response participation in redispatch markets and ultimately in the ancillary services markets for frequency [37] and voltage regulation [38].

Future work will apply the proposed scheduling method for energy planning purposes for renewable energy policy studies in the Western Interconnection beyond the year 2024. The objective will be to determine the most economically beneficial type and capacity of renewable energies in each region such that the interconnection can achieve a target level of greenhouse gas emissions reduction.

\section{Acknowledgments}

This work is supported by grants from Natural Resources Canada (NRCan) and the Pacific Institute for Climate Solutions (PICS), and by funding from the US Department of Energy's Pacific Northwest National Laboratory and SLAC National Accelerator Laboratory. 


\section{Appendix 1: Objective function}

Under the standalone condition, supply and demand quantities are equal, so the clearing price in control area $n$ is:

$$
p_{0_{n}}=\frac{s_{n} p_{\max }-d_{n} p_{\min }}{s_{n}-d_{n}}+\frac{s_{n} d_{n}}{s_{n}-d_{n}}\left(q_{w_{n}}-q_{u_{n}}\right) .
$$

For a non-zero net export $e_{n}=q_{s_{n}}-q_{d_{n}}$, the demand price is equal to the supply price:

$\underbrace{d_{n}\left(q_{d_{n}}-q_{u_{n}}\right)+p_{\max }}_{p_{d_{n}}}=\underbrace{s_{n}\left(q_{s_{n}}-q_{w_{n}}\right)+p_{\min }}_{p_{s_{n}}}=s_{n}(\underbrace{q_{d_{n}}+e_{n}}_{q_{s_{n}}}-q_{w_{n}})+p_{\min }$,

therefore the demand quantity is:

$$
q_{d_{n}}=\frac{p_{\max }-p_{\min }}{s_{n}-d_{n}}+\frac{s_{n} q_{w}-d_{n} q_{u}}{s_{n}-d_{n}}-\frac{s_{n}}{s_{n}-d_{n}} e_{n},
$$

and the clearing price is:

$$
p_{c_{n}}=\underbrace{\frac{s_{n} p_{\max }-d_{n} p_{\min }}{s_{n}-d_{n}}+\frac{s_{n} d_{n}}{s_{n}-d_{n}}\left(q_{w_{n}}-q_{u_{n}}\right)}_{p_{0_{n}}}-\frac{s_{n} d_{n}}{s_{n}-d_{n}} e_{n}=p_{0_{n}}-\omega_{n} e_{n},
$$

so the price vector is:

$$
\mathbf{p}=\mathbf{p}_{0}-\Omega \mathbf{e} .
$$

Accordingly, Eq. (7a) can be rewritten as:

$$
\max \frac{-1}{2} \sum_{n=1}^{N} \omega_{n} e_{n}^{2} \equiv \min \frac{1}{2} \sum_{n=1}^{N} \omega_{n} e_{n}^{2}
$$


Appendix 2: WECC intertie transfer capacity

\begin{tabular}{|c|c|c|c|c|}
\hline $\begin{array}{l}\text { Path } \\
\text { number }\end{array}$ & $\begin{array}{l}\text { From } \\
\text { area }\end{array}$ & $\begin{array}{l}\text { To } \\
\text { area }\end{array}$ & $\begin{array}{r}\text { Minimum } \\
{[\mathrm{MW}]}\end{array}$ & $\begin{array}{r}\text { Maximum } \\
{[\mathrm{MW}]}\end{array}$ \\
\hline$\overline{\mathrm{P} 01}$ & $\overline{\mathrm{AESO}}$ & $\overline{\mathrm{BCH}}$ & -1200 & $\bar{~} 1000$ \\
\hline P03 & PNW & $\mathrm{BCH}$ & -3150 & 3000 \\
\hline P08 & NWMT & PNW & -2150 & 3000 \\
\hline P09 & NWMT & $\mathrm{CO}$ & -2573 & 2573 \\
\hline P14 & ID & PNW & -2250 & 3400 \\
\hline P16 & ID & SPPC & -360 & 500 \\
\hline P18 & NWMT & ID & -256 & 337 \\
\hline P20 & ID & UT & -2250 & 2250 \\
\hline P22 & PNM & $\mathrm{AZ}$ & -2325 & 2325 \\
\hline P24 & $\mathrm{NCA}$ & SPPC & -150 & 160 \\
\hline P26 & $\mathrm{NCA}$ & SCA & -3000 & 4000 \\
\hline $\mathrm{P} 27$ & UT & LDWP & -1400 & 2400 \\
\hline P30 & UT & PSCO & -650 & 650 \\
\hline P31 & PSCO & PNM & -690 & 690 \\
\hline P32 & SPPC & UT & -235 & 440 \\
\hline P35 & UT & NEVP & -580 & 600 \\
\hline P36 & $\mathrm{CO}$ & PSCO & -1680 & 1680 \\
\hline $\mathrm{P} 42$ & IID & SCA & -1500 & 1500 \\
\hline $\mathrm{P} 43$ & LDWP & SCA & -4000 & 4000 \\
\hline P44 & CISD & SCA & -2500 & 2500 \\
\hline P45 & CISD & $\mathrm{CFE}$ & -800 & 400 \\
\hline $\mathrm{P} 46 \mathrm{~N}$ & NEVP & LDWP & -6000 & 6000 \\
\hline $\mathrm{P} 46 \mathrm{~S}$ & NEVP & SCA & -5000 & 5000 \\
\hline P47 & $\mathrm{EPE}$ & $\mathrm{AZ}$ & -1048 & 1048 \\
\hline P48 & $\mathrm{EPE}$ & PNM & -1970 & 1970 \\
\hline P49 & $\mathrm{AZ}$ & NEVP & -10200 & 10200 \\
\hline P59 & $\mathrm{AZ}$ & SCA & -218 & 218 \\
\hline P65 & PNW & LDWP & -3100 & 3220 \\
\hline P66 & PNW & $\mathrm{NCA}$ & -3675 & 4800 \\
\hline P76 & PNW & SPPC & -300 & 300 \\
\hline P78 & UT & PNM & -600 & 600 \\
\hline P79 & $\mathrm{AZ}$ & $\mathrm{UT}$ & -300 & 265 \\
\hline P80 & NWMT & PAWY & -600 & 600 \\
\hline PP1 & PAWY & UT & -1700 & 1700 \\
\hline PP2 & IID & CISD & -150 & 150 \\
\hline PP3 & $\mathrm{AZ}$ & CISD & -1160 & 1650 \\
\hline PP4 & $\mathrm{AZ}$ & IID & -160 & 260 \\
\hline
\end{tabular}




\section{References}

[1] U.S. Department of Energy. Benefits of demand response in electricity markets and recommendations for achieving them. Washington, DC, USA, Tech. Rep, 2006 .

[2] MC Hu, SY Lu, and YH Chen. Stochastic-multiobjective market equilibrium analysis of a demand response program in energy market under uncertainty. Applied Energy, 182:500-506, 2016.

[3] C Zhang, Q Wang, J Wang, M Korpås, and ME Khodayar. Strategy-making for a proactive distribution company in the real-time market with demand response. Applied Energy, 181:540-548, 2016.

[4] T Broeer, J Fuller, F Tuffner, D Chassin, and N Djilali. Modeling framework and validation of a smart grid and demand response system for wind power integration. Applied Energy, 113:199-207, 2014.

[5] N Samaan, R Schellberg, D Warady, S Williams, R Bayless, S Conger, R Brush, T Gossa, M Symonds, K Harris, et al. Analysis of benefits of an energy imbalance market in the NWPP. Pacific Northwest National Laboratory, Richland, WA, PNNL-22877, 2013.

[6] JW Feltes, BD Gemmell, and D Retzmann. From smart grid to super grid: Solutions with hvdc and facts for grid access of renewable energy sources. In Power and Energy Society General Meeting, pages 1-6. IEEE, 2011.

[7] AE MacDonald, CTM Clack, A Alexander, A Dunbar, J Wilczak, and Y Xie. Future cost-competitive electricity systems and their impact on US CO2 emissions. Nature Climate Change, 2016.

[8] WW Hogan. Contract networks for electric power transmission. Journal of Regulatory Economics, 4(3):211-242, 1992.

[9] EPEX Spot. European Power Exchange. www .epexspot. com. [Online; accessed 11-Nov-2016].

[10] S Newell and K Madjarov. Economic evaluation of alternative demand response compensation options. The Brattle Group, 2010.

[11] JR Pierce. Primer on demand response and a critique of FERC order 745, a. Geo Wash. J. Energy \&3 Envtl. L., 3:102, 2012.

[12] J Krutilla. The international Columbia river treaty: An economic evaluation. Water Research, Baltimore: Johns Hopkins, pages 69-97, 1966.

[13] S Stoft. Power system economics. Journal of Energy Literature, 8:94-99, 2002. 
[14] GB Sheblé. Computational auction mechanisms for restructured power industry operation. Springer Science \& Business Media, 2012.

[15] GA Stern, JH Yan, PB Luh, and WE Blankson. What objective function should be used for optimal auctions in the ISO/RTO electricity market? In Power Engineering Society General Meeting, pages 10-pp. IEEE, 2006.

[16] CL Su and D Kirschen. Quantifying the effect of demand response on electricity markets. Transactions on Power Systems, 24(3):1199-1207, 2009.

[17] H Wu, M Shahidehpour, A Alabdulwahab, and A Abusorrah. Demand response exchange in the stochastic day-ahead scheduling with variable renewable generation. Transactions on Sustainable Energy, 6(2):516-525, 2015.

[18] P Siano and D Sarno. Assessing the benefits of residential demand response in a real time distribution energy market. Applied Energy, 161:533-551, 2016.

[19] TB Nguyen, N Samaan, and C Jin. Evaluation of production cost savings from consolidation of balancing authorities in the US Western Interconnection under high wind and solar penetration. In Conference on Technologies for Sustainability, pages 9-14. IEEE, 2014.

[20] JE Price. Benchmarking a reduced test-bed model of WECC region for unit commitment and flexible dispatch. In Power and Energy Society General Meeting, pages 1-5. IEEE, 2013.

[21] A Zakariazadeh and S Jadid. Smart microgrid operational planning considering multiple demand response programs. Journal of Renewable and Sustainable Energy, 6(1):013134, 2014.

[22] M Mazidi, H Monsef, and P Siano. Robust day-ahead scheduling of smart distribution networks considering demand response programs. Applied Energy, 178:929-942, 2016.

[23] MathWorks. Moore-Penrose pseudoinverse of matrix. www.mathworks.com/ help/matlab/ref/pinv.html. [Online; accessed 11-Nov-2016].

[24] J Nocedal and S Wright. Numerical optimization. Springer Science \& Business Media, 2006.

[25] MathWorks. fmincon SQP algorithm. http://tinyurl.com/jycokm9. [Online; accessed 11-Nov-2016].

[26] S Boyd and L Vandenberghe. Convex optimization. Cambridge university press, 2004.

[27] WECC's System Adequacy Planning Department. Integrated transmission and resource assessment- summary of 2015 planning analyses, March 2016. 
[28] WECC's System Adequacy Planning Department. WECC 2024 common case. www . wecc . biz/SystemAdequacyPlanning/Pages/Datasets . aspx. [Online; accessed 11-Nov-2016].

[29] DJ Hammerstrom, R Ambrosio, J Brous, TA Carlon, DP Chassin, JG DeSteese, RT Guttromson, GR Horst, OM Järvegren, R Kajfasz, et al. Pacific northwest gridwise testbed demonstration projects. Part I. Olympic Peninsula Project, 2007.

[30] SE Widergren, K Subbarao, JC Fuller, DP Chassin, A Somani, MC Marinovici, and JL Hammerstrom. AEP Ohio gridSMART demonstration project realtime pricing demonstration analysis. PNNL Report, 23192, 2014.

[31] KP Schneider, E Sortomme, SS Venkata, MT Miller, and L Ponder. Evaluating the magnitude and duration of cold load pick-up on residential distribution feeders using multi-state load models. IEEE Transactions on Power Systems, 31(5):3765-3774, 2016.

[32] F Klügl. A validation methodology for agent-based simulations. In Proceedings of the 2008 ACM symposium on applied computing, pages 39-43. ACM, 2008.

[33] DP Chassin, S Behboodi, C Crawford, and N Djilali. Agent-based simulation for interconnection-scale renewable integration and demand response studies. Engineering, 1(4):422-435, 2015.

[34] P Windrum, G Fagiolo, and A Moneta. Empirical validation of agent-based models: Alternatives and prospects. Journal of Artificial Societies and Social Simulation, 10(2):8, 2007.

[35] S Behboodi, DP Chassin, C Crawford, and N Djilali. Renewable resources portfolio optimization in the presence of demand response. Applied Energy, 162:139-148, 2016.

[36] DP Chassin and D Rondeau1. Aggregate modeling of fast-acting demand response and control under real-time pricing. Applied Energy, 181:288-298, 2016 .

[37] V Lakshmanan, M Marinelli, J Hu, and HW Bindner. Provision of secondary frequency control via demand response activation on thermostatically controlled loads: Solutions and experiences from Denmark. Applied Energy, 173:470-480, 2016.

[38] O Homaee, A Zakariazadeh, and S Jadid. Real time voltage control using emergency demand response in distribution system by integrating advanced metering infrastructure. Journal of Renewable and Sustainable Energy, 6(3):033145, 2014 . 